LBL- -32636

DE93 000637

\title{
Risk Factors for Work-Related Symptoms in Northern California Office Workers
}

\author{
Mark J. Mendell \\ Indoor Environment Program \\ Lawrence Berkeley Laboratory \\ Berkeley, California \\ Program in Epidemiology \\ Department of Biomedical and Environmental Health Sciences \\ University of California \\ Berkeley, California \\ Environmental Epidemiology and Toxicology Program \\ California Department of Health Services \\ Emeryville, California \\ The Industrywide Studies Branch \\ National Institute for Occupational Safety and Health \\ Cincinnati, Ohio
}

October 1991

This work was supported by the Assistant Secretary for Conservation and Renewable Energy, Office of Building and Community Systems, Building Systems Division of the U.S. Department of Energy (DOE) under Contract No. DE-AC03-76SF00098, and by the Health Effecis Component of the University of California Toxic Substances Research and Training Program, and by the Environmental Epidemiology and To.icology Program of the California Department of Health Services. 


\title{
Risk Factors for Work-Related Symptoms in Northern California Office Workers
}

\author{
Copyright $\odot 1991$
}

by

Mark J. Mendell

The U.S. Department of Energy has the right to use this thesis for any purpose whatsoever including the right to reproduce all or any part thereof 


\title{
Risk Factors for Work-Related Symptoms \\ In Northern Callfornla Office Workers
}

by

Mark Judson Mendell

\begin{abstract}
In most episodes of health complaints reported in office buildings in the last twenty years, causal factors have not been identified. In order to assess risk factors for work-related symptoms in office workers, a reanalysis was performed of previous studies, and an epidemiologic study was conducted. The reanalysis of data, from all studies available on work-related symptom prevalence in office workers by type of building ventilation, showed remarkable agreement among studies. Air-conditioned buildings were consistently associated with higher prevalence of headache, lethargy, and eye, nose, or throat problems. Humidification was not a necessary factor for this higher prevalence. Mechanical ventilation without afr-conditioning was not associated with higher symptom prevalence. Guided by these findings, a study was conducted among 880 office workers, within 12 office buildings selected without regard to worker complaints, in northern California. A number of factors were found associated with prevalence of work-related symptoms, after adjustment in a logistic regression model for personal, psychosocial, job, workspace, and building factors. Two different ventilation types were associated with increases in symptou prevalence, relative to workers in naturally ventilated buildings: mechanical supply and exhaust ventilation, without ait conditioning and with operable
\end{abstract}


windows; and air-condicioning with sealed windows. No study buildings were humidified. In both these ventilation types, the highest odds ratios (ORs) found were for skin symptoms (ORs-5.0, 5.6) and for tight chest or difficulty breathing (ORs-3.6, 4.3); increases were also found for chills or fever, fatigue or sleepiness, and eye, nose, or throat symptoms. Increased ORs were not found for symptoms hypothesized to be unrelated to indoor air factors. Additional factors were independently associated with prevalence of work-related symptoms. Certain jobs, use of carbonless copies or photocopiers, sharing a workspace, carpets, new carpess, new walls, and distance from a window were associated with symptom increases. Cloth partitions and new paint were associated with symptom decreases. An OR of 14.3 for association between new carpets and respiratory symptoms, and the substantially reduced ORs for many symptoms with presence of cloth partitions or new paint were striking. These findings confirm and extend previously reported findings, and suggest that indoor air-related symptoms in office workers may be commonly related to factors in indoor air. 
RISK FACTORS FOR WORK-RELATED SYMPTOMS

IN NORTHERN CALIFORNIA OFFICE WORKERS

TABLE OF CONTENTS

TITLE PAGE

COPYRIGHT PAGE

ABSTRACT …

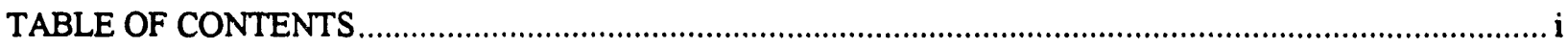

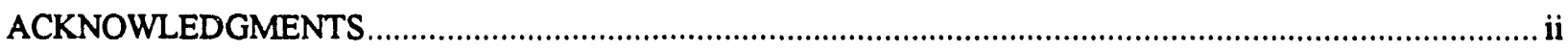

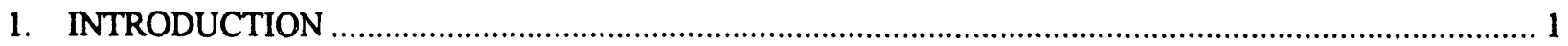

2. REVIEW AND REANALYSIS OF PUBLISHED STUDIES ON VENTILATION TYPE AND WORK-RELATED SYMPTOMS AMONG OFFICE WORKERS.....................................

3. WORK-RELATED SYMPTOMS AMONG NORTHERN CALIFORNIA OFFICE: WORKERS ASSOCIATIONS WITH BUILDING VENTIL ATION TYPE

4. WORK-RELATED SYMPTOMS AMONG NORTHERN CALIFORNIA OFFICE WORKERS: ASSOCIATED WITH PERSONAL, JOB, AND WORKSPACE FACTORS

5. FUTURE RESEARCH ON ACUTE BUILDING-RELATED HEALTH PROBLEMS IN OFFICE WORKERS

REFERENCES 87

APPENDIX 1: SUMMARY OF STUDIES REVIEWED AND REANALYZED

APPENDIX 2: QUESTIONNAIRE AND CONSENT FORM 


\section{ACRNOWLEDGEMENTS}

This work was supported by the Environmental Epidemiology and Toxicology Program of the California Department of Health Services, the Indoor Environment Program at Lawrence Berkeley Laboratory, and the Health Effects Component of the University of California Toxic substances Research and Training Program. I would like to thank Michael Bates, Irva Hertz, Dennis Shusterman, Charles Becker, and numerous others for their comments on the draft manuscript. I would also like to thank the authors of the studies reviewed hereir. for their generous cooperation.

I most particularly want to thank Allan Smith and William Fisk for their continued encouragement and guidance, without which this work would have been much less valuable and immeasurably more difficult. I am also immensely grateful to my parents and other family members, who have patiently supported me along the winding and often difficult road I have travelled. 


\section{INTRODUCTION}

Episodes of vague and nonspecific symptom complaints in office buildings have been reported with increasing frequency since the early 1970s, when the energy crisis led to design and construction of more energy efficient and airtight buildings. Most of these episodes have not been explained even after intensive investigation (6): such episodes, where specific causal exposures or disease mechanisms have not been identified, are now usually referred to as "sick building syndrome" (or SBS). Due to lack of other explanations, these episodes have often been assumed to be psychogenic rather than environmental in cause (30). Buildings known to have such episodes of unexplained worker health problems will be referred to below as "problem buildings."

Years ago, this phenomenon had seemed difficult or impossible to study, for two primary reasons. The first was that known methods of investigation and environmental measurement were usually not informative in these episodes. Contaminants were rarely found at levels above existing health standards. There seemed to be no reason to think that even large studies of many problem buildings would implicate specific environmental factors, given current measurement technology. Yet even repeated failure to find environmental associations could still not exonerate all environmental factors. 
The second major problem was that specific diseases, or even any objective evidence of health effects, were rarely found in these episodes; only subjectively reported symptoms seemed unusually frequent. However, interpreting subjective symptom reports from the worried occupants of a problem building has always left researchers uncertain how much reporting stemmed from concern, and how much from actual underlying health effects. Yet, on the other hand, it did not seem likely that one could do a study without the problem buildings, because then what would one be studying? If either known diseases, or exposures at levels known to be harmful, had turned out to be characteristic of the SBS phenomenon, traditional investigation methods would have elucidated it long ago. But such did not seem to be the case, as the problem did not seem to lie where our usual measurements cast light.

It may still be a public health necessity in some cases to investigate problem buildings, in order to respond to concerned groups, to rule out known toxic exposures, and in some cases to be able to discover and correct specific problems. But such investigations at this point are unlikely, by themselves, to help us explain the larger question, for all the reasons mentioned, and also because interpretation of information gathered is difficult without a comparison group.

As essentially all studies of the SBS problem reported from the U.S. have been limited to just this kind of 
investigation of individual problem buildings, the U.S. literature has not shed much light on the larger phenomenon. For a long time, there seemed to be no simple way to study this problem; in fact, it was not even clear that environmental exposures were involved. However, beginning in 1984 , studies of a different kind began to be reported from Europe: cross-sectional studies of multiple office buildings selected without regard to worker complaints. Findings from these were rather surprising, showing that more office buildings than expected had a relatively high prevalence of symptoms, of the type usually reported in problem buildings, and that increased prevalence of these same symptoms was found, in these mostly non-complaint buildings, to be systematically associated with certain ventilation types $(12,16,17,22)$. This made it seem both more likely that there might be some types of environmental exposures involved, and that we might learn about sick buildings by studying non-sick buildings, thus avoiding some problems of biased reporting.

There were, though, a number of apparent inconsistencies in the reported findings, and a number of ways in which the studies could not really be compared, because of different definitions and measurement methods used. A review of these studies was undertaken, including a standardized reanalysis of data from each of them, so that results were comparable across studies. This required combining information from all published or reported 
versions of each study, and where this was not sufficient, obtaining other information directly from the study authors.

The reanalysis showed remarkably consistent patterns of association across all studies, with increases of workrelated symptom prevalence associated with air-conditioned office buildings (i.e., with chilling or cooling of indoor air), relative to buildings with natural ventilation (i.e., with no mechanical ventilation or air-conditioning).

It was not clear what specific factors associated with air-conditioned buildings might have been responsible for the symptom prevalence increases. If bias and confounding factors did not explain the findings, then they were presumably due to chemical, biological, or physical factors related to ventilation systems. Data from these studies did not allow assessment of specific environmental hypotheses, but they suggested the possibility that central airconditioning systems might be risk factors for the production or dissemination of contaminants related to worker health problems.

The findings also suggested that, at least in some countries, increases in building-related symptoms in offices may not be unusual events, but relatively common events not usually attributed to buildings. A corollary of this would be that known "problem" buildings may constitute only the visible fraction of all the buildings with unusually high levels of worker symptoms. There is almost no information 
available on how symptoms in problem buildings relate to the distribution of symptom levels within buildings generally.

As an estimated $50 \%$ of the U.S. workforce works in, office buildings, the size of the population potentially affected makes the problem important, even if serious illness is not involved, - In addition, there may be some chronic component to this problem, perhaps a respiratory or generally allergic component. And the possibility of reduced productivity makes this of economic interest as well.

Because no cross-sectional studies of the type reported from European countries had been reported from the U.S., and yet we had numerous reported episodes of apparent indoor air-related illness episodes, conducting such a study in the U.S. seemed potentially valuable. An initial effort was performed in California as a collaboration between the California Department of Health Services and the Indoor Environment Program at Lawrence Berkeley Laboratory. Our study focused on specific contrasts of interest (a number of specific building, workspace, and job activity factors), while controlling as many other variables as possible, either in the design or in the analysis.

since specific environmental measurements had, in previous cross-sectional studies, shown little association with symptom prevalence, and as these measurements were very costly, our study included few of these. Analysis of environmental measurements, performed by staff in the Indoor 
Environment Program at Lawrence Berkeley Laboratory, will not be covered within this dissertation.

Chapter 2 of this dissertation will describe results of the reanalysis of previously reported studies. Chapter 3 will discuss findings from the California study regarding work-related symptoms and building ventilation type, and Chapter 4 the findings regarding work-related symptoms and a number of job and workspace factors. Chapter 5 will summarize previous chapters and discuss implications for future research. 
2. REVIEW AND REANALYSIS OF PUBLISHED STUDIES ON VENTILATION TYPES AND WORK-REIAITED SYMPTOMS AMONG OFFICE WORKERS ${ }^{+}$

Health problems and non-specific symptom complaints apparently related to buildings or indoor air, sometimes referred to as "sick building syndrome" or "tight building syndrome", have been recognized for over fifteen years (1). Though particular chemical (2), biological (3), physical (4), or psychological (5) factors have been implicated in some episodes, specific causes have generally not been identified (6). Studies of this problem to date, generally carried out in buildings identified by worker complaints (deferred to herein as "complaint" buildings), have demonstrated mostly what these episodes are not. They are not caused by known toxins at concentrations exceeding current health standards, nor are they generally associated with known diseases. We still have little idea how frequently the excess symptoms reported in such episodes actually occur among office workers, or what, if any, chronic health problems in this population are related to office buildings.

It is difficult to study a phenomenon characterized only by self-reported non-specific symptoms, with no + This chapter has previously been published in the American Journal of Public Health $(1990 ; 80: 1193-1199)$ as "Consistent Pattern of Elevated Symptom Prevalence in Air-conditioned Office Buildings: A Reanalysis of Epidemiologic Studies." It appears here with the permission of the Journal, which holds the copyright. 
accepted syndrome definition or objective tests available. A major weakness of investigations in buildings with widely recognized worker complaints is that occupant concerns are likely to upwardly bias symptom reporting, thus distorting the only outcome available for study. Until the development of useful objective tests, it will therefore be preferable to study buildings without recognized worker complaints (referred to herein as "non-complaint" buildings).

Reports on building-related health problems in the United States are almost without exception case studies of complaint buildings $(2-4,7-10)$; only one study compared the building under investigation to even a single non-complaint building (11). A number of recent European studies, however, have provided data from noncomplaint buildings on relations between work-related symptoms in office workers and type of building ventilation (12-26). Preliminary review of the European studies shows that mechanical ventilation, relative to natural ventilation, has been associated with increases (12-16), with decreases (17), and with no differences (22) in work-related symptoms; air-conditioning, relative to mechanical ventilation without airconditioning, has been associated with increases (17) and with no differences (16) in symptoms. Previous reviews of the literature on illness episodes in office buildings 
(6,27-39) have summarized available studies but have not discussed these discrepancies.

This paper presents a reanalysis of data from noncomplaint building studies. The purpose was to determine if there were consistent ralations between prevalence of specific symptoms and certain blilding ventilation factors: mechanical ventilation, air conditioning, and humidification. Though differences between the original studies did not allow direct comparison of results, additional information obtained from study authors allowed creation of a standardized set of ventilation categories, calculation of prevalence odds ratios, and comparison of findings across studies.

\section{METHODS}

\section{Belection of studies for Reanalysis}

Studies of work-related symptoms in office workers were selected from the literature, using specific eligibility criteria. For inclusion in this reanalysis it was required that:

- studies compared multiple non-complaint office buildings;

- data allowed comparison of prevalence for specific work-related symptoms between buildings of different ventilation type; and

- dața were available allowing classification of buildings as naturally or mechanically ventilated, 
as air-conditioned or not air-conditioned, and as humidified or not humidified.

Six studies of worker symptoms in multiple office buildings (12-26) were included in this reanalysis. The studies included were all cross-sectional and compared work-related symptom prevalence in buildings with different ventilation types to a baseline symptom prevalence in naturally ventilated buildings. All studies tested for statistical independence of ventilation categories and symptom prevalence (using chi square or analysis of variance tests) but used no epidemiologic effect measures (such as prevalence ratios or odds ratios). Five studies were conducted in the United Kingdom, and one in Denmark. (Findings of the six studies are summarized in the Appendix 1.)

\section{Ke sbods of Analysis}

Five standard categories of building ventilation type were established, as described in Table 1. Information for this classification was extracted from published materials; where necessary, additional information was obtained directly from the authors, and subsequent classification of buildings was confirmed with them. * Ultimately, sufficient information was available for unequivocal classification of all buildings from the

* personal communications: M. Finnegan, S. Burge,

A. Pickering, A. Robertson, J. Harrison, 0 . Valbjorn. 
six studies into this common set of categories. Correct conversion of ventilation categories in the original studies to the ventilation categories in this reanalysis was not always straightforward; in such cases, the appropriate conversions are provided in footnotes to Table 2, along with publications from which the data were obtained.

Symptoms were organized into four groups: lower respiratory (tight chest, difficulty breathing, shortness of breath, wheeze, and flu-like symptoms): upper respiratory/mucus membrane (nose, throat, and eye symptoms); central nervous system (headache and lethargy); and skin (dry skin, itching skin, and skin rash).

From sample size and prevalence data reported for either individual buildings or groups of buildings in each study, numbers of subjects with and without each specific work-related symptom were calculated within each category of building ventilation type. Prevalence rates were then calculated. "Work-related symptoms" in all studies referred only to symptoms reported as improving on weekends or days away from work (and in study 1 and parts of study 2 , also as having begun or worsened since starting work in the current building). Symptom frequency requirements varied between studies.

Baseline symptom prevalence varied widely between studies. Using the naturally ventilated building 
category as the reference group within each study, prevalence odds ratios and $95 \%$ test-based confidence limits (31) were calculated from prevalence rates for each work-related symptom within each of the other ventilation categories. The prevalence odds ratio was chosen as the most informative epidemiologic effect measure for cross-sectional prevalence data $(32,33)$.

\section{RESUITS}

Table 2 gives the sample sizes for each study reviewed, in tarms of number of workers and number of buildings in each ventilation category.

Table 3 gives prevalence data for specific workrelated symptoms, as calculated for each study using the new building ventilation categories.

Table 4 gives prevalence odds ratios (PORs) for each work-related symptom in each ventilation category. symptom prevalence in category II buildings (with simple mechanical ventilation) was comparable to that in category I buildings or lower, with one exception (headache prevalence in study 4, based on only one building in category II). This was in sharp contrast to the general pattern of higher symptom prevalence in airconditioned buildings (categories III, IV, and V) found in all six studies.

The prevalence of central nervous system and upper respiratory/mucus membrane symptoms was almost without 
exception higher in the air-conditioned buildings than in the naturaliy ventilated buildings. Data on lower respiratory problems were relatively sparse and less. consistent. Data on skin-related symptoms suggested higher prevalence in air-conditioned buildings. Data on differences between air-conditioned buildings with different kinds of humidification were mixed. In studies 1 and 3 , where these data were available, symptom prevalence in buildings with steam humidification was similar to that in those with no humidification. There was some suggestion in both studies of higher symptom prevalence in buildings with water-based humidification relative to both categories III and IV. For 18 of the 21 symptoms assessed between these two studies, point estimates in category $V$ equalled or exceeded those in both categories III and IV.

In study 2 , on the other hand, symptom prevalence in air-conditioned buildings with water-based humidification was generally comparable to or lower than that in airconditioned buildings without humidification. More complete data from this study, however, were presented at a scientific meeting. They showed consistently lower symptom prevalence in air-conditioned buildings with water-based humidification than in those without humidification: symptom prevalence was still 
substantially higher than in naturally ventilated buildings. * *

Buildings without natural ventilation may be sealed (i.e., have non-operable windows) or not. Although sufficient information was not available to allow incorporation of this factor into ventilation categories used for reanalysis, enough information was available to show a very strong relation between the presence of airconditioning and presence of sealed windows in the buildings studied: only 1 of the 48 non-air-conditioned buildings had sealed windows, whereas 52 of the 57 airconditioned buildings had sealed windows. Thus, given the limits of these data, symptom increases found to be associated with air-conditioned buildings may more appropriately be regarded as associated with airconditioned, sealed buildings.

\section{DISCOSSION}

This reanalysis suggests that sealed buildings with air-conditioning are associated with higher prevalence of work-related headache, lethargy, and eye, nose, and throat symptoms than unsealed buildings with no airconditioning, and that the higher symptom prevalence associated with sealed, air-conditioned buildings occurs even in the absence of humidification. It also suggests ** J. Harrison, presented at Indoor Air Quality 89, San Diego, CA, April 17-20, 1989. 
that although air-conditioned buildings with steam humidification are associated with symptom prevalence no higher than air-conditioned buildings without humidification, air-conditioned buildings with waterbased humidification may be associated with higher prevalence of eye, nose, and throat symptoms than those with steam humidification.

Apparent discrepancies in the original reports were resolved by reclassification based on new information from authors of the studies. Buildings described as mechanically ventilated were actually air-conditioned without humidification in studies 1 and 2 , and simply mechanically ventilated in study $3 ;$ in study 6 , they were simply mechanically ventilated or, in one case, airconditioned with water-based humidification.

The prevalence of some work-related symptoms was strikingly high in several studies in even the least problematic office buildings, suggesting a measurement problem. High prevalence of lethargy in category I buildings in studies 3 and 5 (50\% and 62\%) in fact reflects a very broad definition of "work-related" symptoms in these two studies, the least restrictive such definition in all studies reviewed (see Appendix 1). (That such high prevalence resulted from specifics of the study protocol is evident from the fact that study 5 remeasured buildings from study 1 with the protocol from study 3 , and obtained prevalence estimates two to four 
times those in study 1, comparable to those in study 3 (21).) Symptom prevalences reported in study 6, also somewhat high, represented combinations of two to three specific symptoms assessed (10). Such differences emphasize the need for standardized questionnaire design and data reporting.

One must be cautious in generalizing results of this reanalysis. Relationships found in these studies from the United Kingdom and Denmark may not occur in other countries with differences in climate or in the design and operation of buildings and ventilation systems.

Also, limitations in the data restrict conclusions that can be drawn from this reanalysis, due to a variety of possible biases in each study.

Bias from selection of buildings seems unlikely, as buildings in all studies were selected independently of worker complaints. Response bias among workers also seems unlikely, as response rates were high in $a^{\prime \prime l}$ studies. (See Appendix 1.) Some selection bias due to cross-sectional study design is possible as workers who left the workplace due to illness or discomfort were not included, but this would lead to underestimation of any real effects.

Because "negative" (non-significant) studies are generally less likely to be submitted or accepted for publication, reviews of the literature are likely to contain a disproportionate number of studies with 
positive findings, relative to all studies actually performed on that subject $(34,35)$. Publication bias may in this way have inflated the magnitude of associations in this review; however, larger studies are considered less prone to this bias (35), and PORs for airconditioned buildings were consistently elevated even in the largest studies reviewed. Furthermore, a consistent "negative" finding of this reanalysis was not subject to such bias: symptom prevalence in simply mechanically ventilated buildings was no greater than that in naturally ventilated buildings.

Possible information biases include reporting or interviewer bias, and misclassification. Reporting or interviewer bias, due to increased worker or interviewer concerns about health in sealed, air-conditioned buildings, could have increased frequency of reported symptoms in such buildings and thus led to overestimation of odds ratios. This bias cannot be ruled out.

Awareness of the research hypothesis by interviewers or subjects could have had a similar effect. Interviewers were used only in study 1 , so subjects in other studies could only have inferred hypotheses from the self-administered questionnaires. In study 1 , with the highest PORs of all studies reviewed, interviewers conducted most interviews without knowledge of the buildings where subjects worked, and researchers had no 
prior hypotheses regarding ventilation type and symptoms other than lower respiratory (12).

Misclassification bias could have occurred from . crude classification of the very complex ventilation systems found in large buildings. The resulting nondifferential misclassification, however, would have led to underestimation of any real effects.

A number of potential confounding factors could have affected results. Some non-building factors known to be relatsd t:0 symptom reporting $(17,19,22)$, such as particular social and work environments, gender, job types, workplace smoking, and season of measurement could have introduced confounding if consistently associated with particular ventilation types. There is no evidence that these factors were related to building ventilation type in the buildings studied.

Studies 2,4 , and 5 reported no assessment of potential confounding factors $(16,20,21)$. Study 1 reported only that smoking prevalence was similar in all buildings studied (12). For study 3 , Hedge et al (19) performed a multivariate analysis examining simultaneous association of a number of factors with total number of symptoms reported by each individual. They reported that higher overall symptom prevalence was associated with air-conditioned buildings, independently of associations also found between symptom prevalence and various 
individual, psychological, occupational, and architectural factors.

For study 6 , a multivariate analysis found that, gender, job category, work activities, and psychosocial job factors were associated with work-related symptoms. Differences in symptom prevalence between buildings, however, remained substantially the same after multivariate adjustment, with symptom prevalence still highest in the single category $\mathrm{V}$ building (23).

Some building-related factors may have caused confounding. Air-conditioned buildings, being on average newer than naturally or simply mechanically ventilated buildings, will be more likely to contain fluorescent lighting $(21,36)$, inner offices distant from windows, with no natural light (21), "open-plan" office layouts (20), newer synthetic materials which emit various organic compounds (30), and materials with high absorptive surface area (such as carpets and clothcovered partitions) capable of accumulating and rereleasing physical, chemical, or biological contaminants $(25,29,30,37)$. To produce spuriously the associations found, these factors would have to be strongly related to both symptom prevalence and ventilation type (38). This possibility could not be evaluated in the studies reviewed here.

The patterns of association in this reanalysis suggest that symptom reporting is systematically related 
to still unidentified factors in sealed, air-conditioned buildings. If bias or confounding factors are not responsible for these patterns, these symptom increases may represent one or more as yet unidentified ventilation-related illness syndromes. Possible ventilation-related risk factors include inadequate fresh air ventilation, reduced thermal comfort, use of chemicals within ventilation systems to kill biologic agents (27), and recirculation of infectious (39) or allergenic (30) biologic agents. Sufficient environmental data were not available from the studies reviewed to evaluate these factors. (See Appendix 1.) Results of this reanalysis are consistent with increased exposure of workers to biologic aerosols from water within the ventilation system (i.e., on or under air-conditioning chiller coils, which dehumidify ventilation air, and in water-based humidification systems) $(17,30)$. Inconsistent associations found between symptom prevalence and water-based humidification may reflect a dual effect of such systems: reduced risk of respiratory infections from humidification generally (40), but increased risk of respiratory sensitization to biological contaminants (as in humidifier fever or hypersensitivity pneumonitis) from water-based humidification specifically (41).

In conclusion, the reanalysis of epidemiologic studies presented here suggest that, at least in some 
countries, increases in building-related symptoms in offices may not be unusual events, but relatively common events not usualiy attributed to buildings. Future study of this problem, beyond investigation of complaint buildings, is advisable. 
TABLE Y-oullding Ventliation Categorien for Comparieon Acroea Studien

\begin{tabular}{|c|c|c|c|c|c|}
\hline \multirow[b]{2}{*}{ Ventilation Charectoristica } & \multicolumn{5}{|c|}{ Building Ventilation Catepories } \\
\hline & Natura" & $\begin{array}{c}11 \\
\text { Simple } \\
\text { Mochanical"• }\end{array}$ & $\begin{array}{l}\text { III } \\
\text { Air-Conditioned } \\
\text { No Humidificer } \\
\text { tion }\end{array}$ & $\begin{array}{l}\text { N } \\
\text { Arr-Conditioned } \\
\text { Steam Humidi } \\
\text { fication }\end{array}$ & $\begin{array}{c}V \\
\text { Arr-Conditioned } \\
\text { Water-Based } \\
\text { Humidification }\end{array}$ \\
\hline $\begin{array}{l}\text { Mechanical ventiation } \\
\text { Air-conditioning } \\
\text { Steam humidification } \\
\text { Drip, spray, or eveporative } \\
\text { humidification }\end{array}$ & $\begin{array}{l}\text { No } \\
\text { No } \\
\text { No } \\
\text { No }\end{array}$ & $\begin{array}{l}\text { Yos } \\
\text { No } \\
\text { No } \\
\text { No }\end{array}$ & $\begin{array}{l}\text { Yeo } \\
\text { Yea } \\
\text { No } \\
\text { No }\end{array}$ & $\begin{array}{l}\text { Yes } \\
\text { Yee } \\
\text { Yee } \\
\text { No }\end{array}$ & $\begin{array}{l}Y=0 \\
Y=0 \\
\text { No } \\
\text { You }\end{array}$ \\
\hline
\end{tabular}

opereble mondows only

"ducted arthow without cooting or chilling

TABLE 2-Study Sample slzee by Bullding Ventilation Catiogon

\begin{tabular}{|c|c|c|c|c|c|c|}
\hline \multirow[b]{2}{*}{ Study } & \multirow[b]{2}{*}{$\begin{array}{l}\text { Sampling Unit } \\
\text { (Total N) }\end{array}$} & \multicolumn{5}{|c|}{ Bullding Ventilation Categories } \\
\hline & & $\begin{array}{c}\text { Naturat' } \\
\text { (N) }\end{array}$ & $\begin{array}{l}\text { II } \\
\text { Simple } \\
\text { Nechenicale. } \\
\text { (N) }\end{array}$ & $\begin{array}{c}\text { III } \\
\text { Ar-Conditioned } \\
\text { No } \\
\text { Humidification } \\
\text { (N) }\end{array}$ & $\begin{array}{c}\text { N } \\
\text { Air-Conditioned } \\
\text { Stoam } \\
\text { Humidification } \\
\text { (N) }\end{array}$ & $\begin{array}{c}\text { V } \\
\text { Air-Conditioned } \\
\text { Water-Based } \\
\text { Humidification } \\
\text { (N) }\end{array}$ \\
\hline $\begin{array}{l}10 \\
2^{\infty} \\
3^{\infty} \\
4^{+} \\
5^{n+} \\
6^{n t+}\end{array}$ & $\begin{array}{l}\text { Workers (951) } \\
\text { Buildings (8) } \\
\text { Workers (2587) } \\
\text { Buildings (27) } \\
\text { Workers (4373) } \\
\text { Buildings (47) } \\
\text { Workers (1332) } \\
\text { Buildings (5) } \\
\text { Workers (108) } \\
\text { Buildings (2) } \\
\text { Workers (2778) } \\
\text { Buildings (14) }\end{array}$ & $\begin{array}{r}259 \\
3 \\
537 \\
8 \\
442 \\
11 \\
208 \\
2 \\
47 \\
1 \\
1168 \\
6\end{array}$ & $\begin{array}{l}- \\
- \\
- \\
844 \\
7 \\
118 \\
1 \\
= \\
1430 \\
7\end{array}$ & $\begin{array}{r}73 \\
1 \\
507 \\
6 \\
1017 \\
10 \\
= \\
= \\
- \\
-\end{array}$ & $\begin{array}{l}91 \\
1 \\
= \\
421 \\
- \\
= \\
= \\
=\end{array}$ & $\begin{array}{r}528 \\
3 \\
1543 \\
13 \\
1549 \\
15 \\
1008 \\
2 \\
59 \\
1 \\
182 \\
1\end{array}$ \\
\hline
\end{tabular}

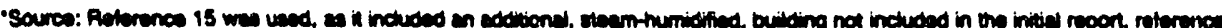

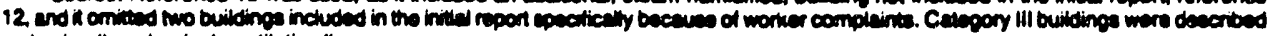
cos heving "mechanicel vemiletion."

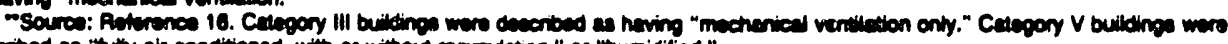

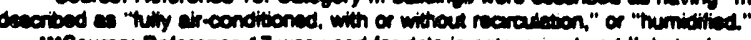

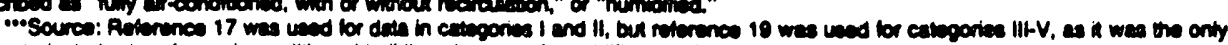
reoon to include deta trom eir-conditioned buldinge by ivpe of numiditication, ber all symptome.

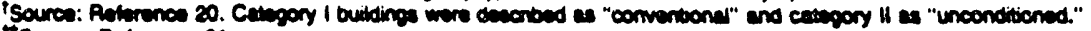

Hecoures: Retwrences 21.

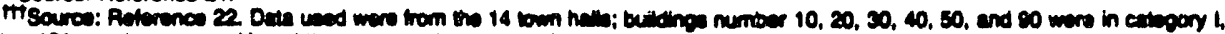

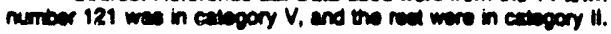




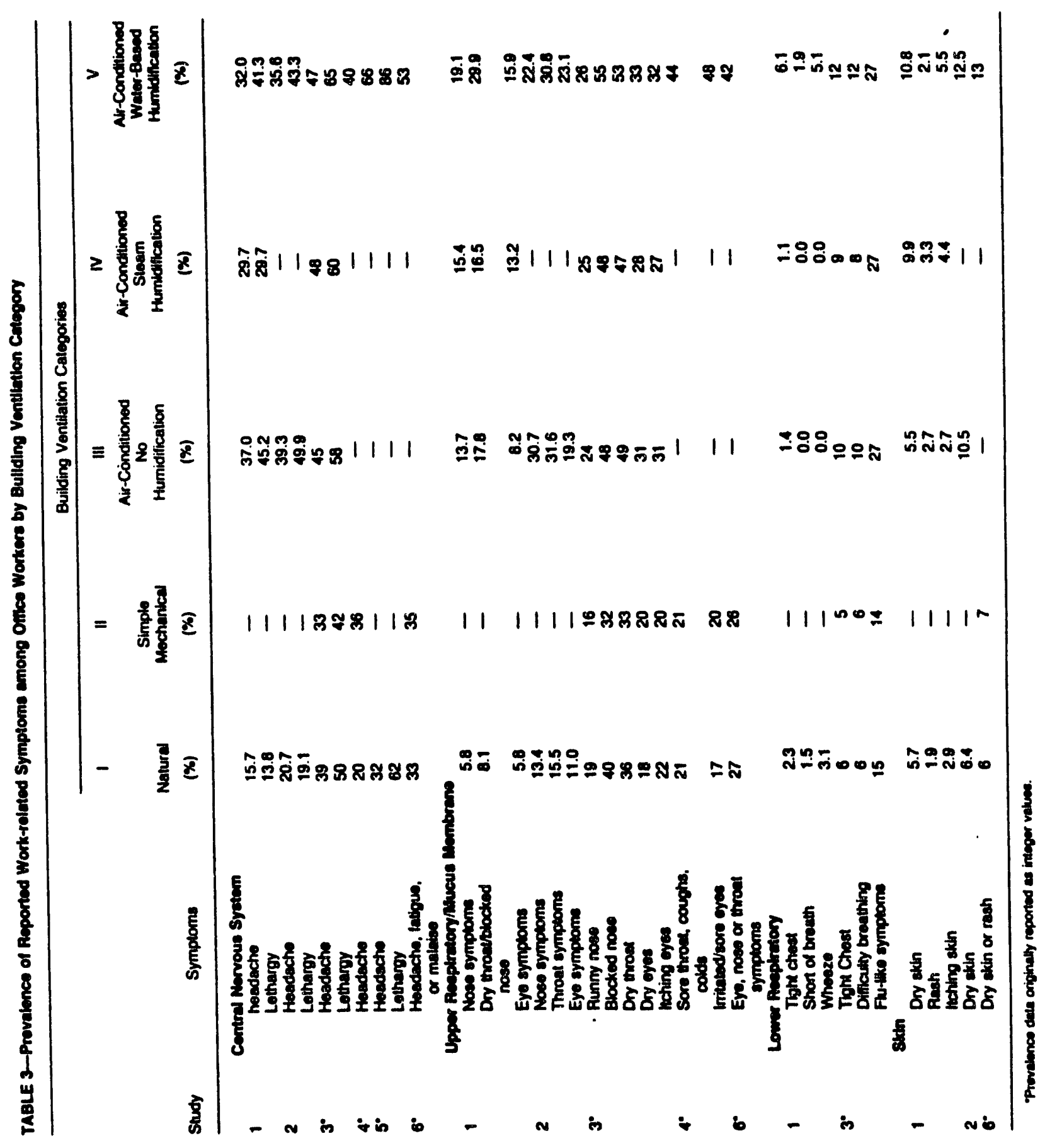




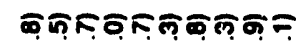

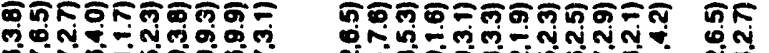

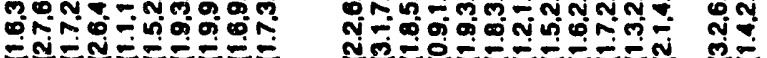
$\Xi \mathbb{N}=\mathbb{N}====$

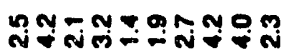

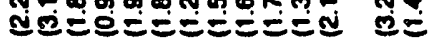

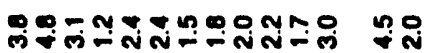

ริธศกสสิ ำ क⿻

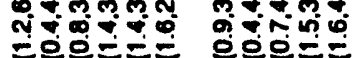
ees=

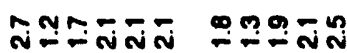

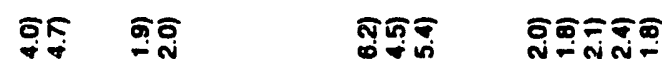

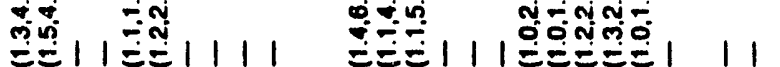

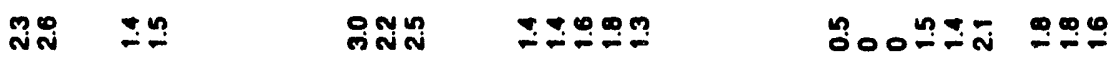

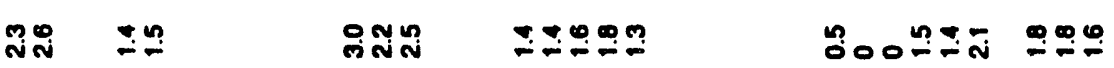

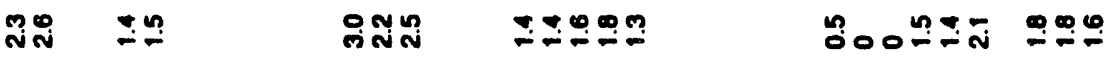

จ

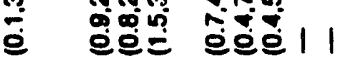

\section{Кำต̄ตฺต

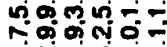

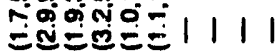

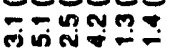

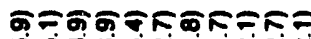
ำ

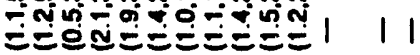
on no 우웅

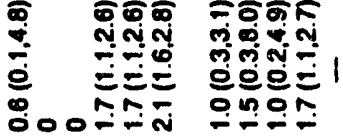

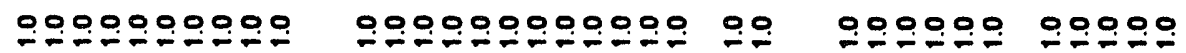

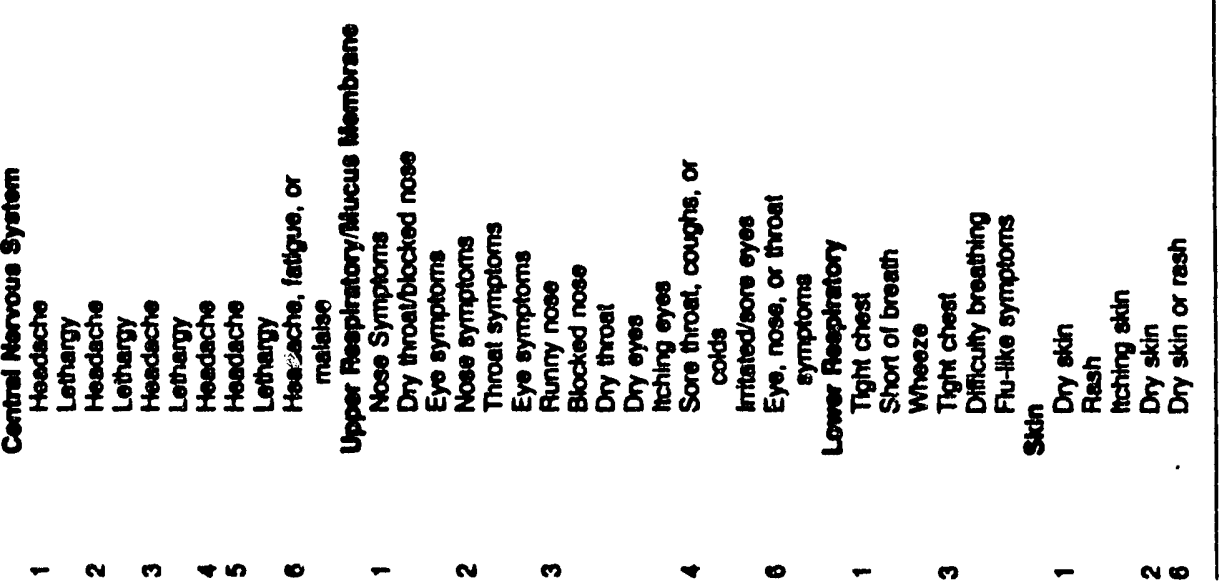


3. WORK-REIATED BYMPTOMS AMONG NORTHERM CALIFORNIA OFFICE WORLERS: A88OCIATIONS WITH BUIIDING VENTIIATION TYPE

Episodes of health complaints among office workers have been reported with increasing frequency during the last 20 years (1). Although indoor air quality has often been considered the likely cause of these episodes, investigations have generally not identified either environmental contaminants at levels above existing health standards, thermal comfort parameters outside acceptable ranges, or objectively measurable changes in health status (30). The name "sick-building syndrome" (SBS) has been applied to those episodes in which specific diseases and causal mechanisms have not been established (30). As investigations of SBS thus yielded only reports of common symptoms not indicative of particular diseases or exposures, along with an absence of environmental findings, specific episodes have often been attributed to psychological factors (6).

Early studies of SBS focused entirely on buildings in which workers had expressed persistent and severe complaints. Interpretation of data from workers in these buildings was difficult, because the psychological state of these workers in "sick" buildings may have biased their symptom reporting upward, because traditional industrial hygiene approaches were not informative, and because comparison data from "non-sick" buildings was not available. More recently, a number of European studies have examined 
office workers in buildings chosen without regard to worker complaints $(15-17,20-22,44,50,66 ; M$. Mendell, unpublished reanalyses of data from 51). All of these studies have found the prevalence of reported symptoms at work to be consistently higher among workers in air-conditioned buildings (i.e., those with cooling of inside air) than among those in naturally ventilated buildings (44). These studies, however, did not identify specific higher pollutant exposures in the air-conditioned buildings.

For workers within buildings with mechanical ventilation but without air-conditioning, research findings have been less consistent. Early European studies produced conflicting findings, but a reanalysis of their data showed, consistently across all studies, no increase in work-related symptom prevalence among workers in these buildings, relative to those in naturally ventilated buildings. (44). More recent reanalyses, however, using more precise categories, have found increases in symptom prevalence associated with mechanical supply and exhaust ventilation, but not with mechanical exhaust ventilation alone (52; $M$. Mendell, unpublished reanalyses of data from 51).

The consistent associations found between symptom prevalence and specific ventilation types suggest that, rather than being an entirely psychologically-based phenomenon, SBS may be related to unmeasured environmental factors that are related to ventilation type. Furthermore, the correspondence between the symptoms found at higher 
levels within certain ventilation types and the typical SBS symptoms $(44,30)$ suggests that SBS may be the visible component of a larger phenomenon. It has been difficult, however, to develop case definitions for specific SBSrelated illness syndromes based only on symptom reports, or to establish associations between health problems and specific environmental exposures.

In previous cross-sectional studies of office workers, the most consistent findings have been of relationships between elevated symptom prevalence and a variety of likely surrogates of exposure, such as air-conditioning and humidification systems (44), or carpets, even when no measured contaminants exceeded standards (52). In these studies, as in most investigations of problem building episodes, symptom reports have rarely been associated with any environmental contaminants at levels above existing standards $(4,6)$. Some recent studies have suggested relationships between symptoms and office worker exposures which are below existing standards $(58,59,56,60)$. The exposures relevant to this problem thus may not be adequately assessed by current measurement approaches or controlled by existing standards.

The relationships of worker symptoms to ventilation type and other environmental factors, in U.S. buildings not selected because of worker complaints, have not been previously studied. To make an initial assessment of these and other relationships, we studied workers in twelve 
California office buildings selected without regard to complaint status. In particular, we were interested in investigating independent associations of work-related. symptoms with particular aspects of building design, such as mechanical ventilation supply, air-conditioning, and sealed windows, after adjustment for potential confounding factors including personal, job-related, and workspace factors. study objectives, design, and methods have been previously reported in detail (45).

\section{MATERIALS AND METHODS}

\section{study design and population}

We studied workers within public office buildings of three different ventilation types, within a limited geographic region in northern California, between June and September, 1990. Building selection was based upon an assembled list of city and county owned office buildings in the San Francisco Bay Area. Jails, hospitals, and stations for police, highway patrol, and firefighters were eliminated from the list as non-representative of most office buildings. The list was further narrowed to include only buildings meeting the following criteria: located in san Francisco, Contra Costa, or western Alameda Counties; containing more than 10,000 square feet of currently occupied office space with at least 45 full-time office workers (including at least 10 clerical workers); not containing unusual pollutant sources, or undergoing major 
renovations or large-scale occupant relocations; and having one of three types of ventilation:

1) natural ventilation with operable windows;

2) mechanical supply and exhaust ventilation with no air conditioning and no humidification, and with operable windows; and

3) mechanical supply and exhaust ventilation with airconditioning and no humidification, and with sealed windows (built as non-operable).

These are referred to below as: 1) naturally ventilated, 2) mechanically ventilated, and 3) air-conditioned.

one eligible building without air-conditioning contained two large spaces which were, with respect to their ventilation, essentially isolated from each other and the rest of the building. One had natural and the other mechanical ventilation. We treated these as spaces from separate buildings (\#11 and 12: see table 1).

We obtained permission to study workers in three of four eligible naturally ventilated buildings, in three of four eligible mechanically ventilated buildings, and in six of eleven eligible air-conditioned buildings. No reason for denying access was given for the naturally or mechanically ventilated buildings. Reasons given for refusals in the five air-conditioned buildings were, for four, serious worker/management tensions about health or comfort in the building, and for one, heavy workloads not allowing time for questionnaire completion. We studied workers in the 12 
buildings to which we were granted access, out of 19 eligible. These consisted of three naturally ventilated, three mechanically ventilated, and six air-conditioned. buildings (see table 1). Smoking within all buildings on our list was prohibited by building policy, except in small designated areas.

Although in any building there may be workers who worry that the indoor air quality affects their health, such worry becomes so prominent in some buildings that it seems to dominate many workers' experiences of working there. Although formal criteria for recognizing such buildings have not been defined, we refer to such buildings, following cone and Hodgson (46) and Kreiss (30), as "problem" buildings. Though buildings were neither sought nor excluded on the basis of problem status, one of the air-conditioned buildings included (\$2) was found to be a classic problem building. In this building, severe and persistent occupant health complaints dating back to initial building occupancy 12 years before had led to investigations by various agencies, but no investigation had identified causes or provided solutions for the worker dissatisfaction. Because of the possibility that symptom reports from this building had been affected by unusual levels of occupant concern, we adjusted in our analysis for problem building status.

Within each study building, we included workers from specific spaces rather than from the entire building. Study 
spaces were selected so that the working environments in different buildings would be as similar as possible. Open office areas with 45 or more workers were selected where available, along with any adjoining enclosed offices. Where this was not possible, smaller spaces containing a total of at least 45 workers were combined.

Eligible workers were all those in the study spaces, excluding any who had worked in the building less than three months, any who generally worked in the building less than 20 hours per week, and any who were absent from the office for one week or more during our study period.

Information about buildings was obtained from occupant records, by physical inspection, and from interviews with building management and engineering staff. Questionnaire

The questionnaire used in our study (see Appendix 2) was a modified version of a self-administered questionnaire from a study of several U.S. Govermment buildings in Washington, D.C. (47). The questionnaire asked about the frequency of 15 symptoms occurring at work, during the previous week and also during the previous year, and whether each symptom changed when the respondent was not at work. other questions assessed various health, demographic, psycho-social, and work-related parameters.

Questionnaires were distributed to all workers in each selected space at the beginning of a work week for return in sealed envelopes into locked boxes supplied in each study 
space. Workers not returning completed questionnaires or written refusals were recontacted up to three times by phone before they were considered non-respondents.

\section{Analytical methods}

For the analyses presented here, we defined a workrelated symptom as one reported to have occurred often or always when at work the previous year, and also to have improved when away from work. Seven symptom groups were formed by combining related symptoms (see table 2 ). Reporting at least one work-related symptom within a symptom group constituted a positive response for that group. six of these groups (eye, nose, or throat symptoms; chest tightness or difficulty breathing; chills or fever; fatigue or sleepiness; headache; dry or itchy skin) were formed from 11 symptoms hypothesized, on the basis of previous reports, to be related to indoor air factors and ventilation type. one group ("non-indoor air related" symptoms) was formed from three symptoms not previously reported as associated with indoor air factors or ventilation type -- toothache, earache, and pain in neck or shoulder. These symptoms were included in the questionnaire in an attempt to assess symptom over-reporting.

Analyses were performed using the statistical packages SAS $6.06(48)$ and BMDP/90 (49). Analyses reported here assess relationships between work-related symptom prevalence (for the seven symptom groups) and building ventilation categories, using the naturally ventilated buildings as a 
reference category. A number of personal, psychosocial, job, and workspace characteristics were considered as covariates.

Crude odds ratios (ORs) for associations between workrelated symptoms and ventilation type were calculated using the Mantel-Haenszel estimate. In view of the a priori hypotheses that symptom prevalence would be lowest within the naturally ventilated buildings, one-sided $p$ values were calculated by halving $\mathrm{p}$ values from the Mantel-Haenszel test of association. $90 \%$ confidence intervals were calculated, using the method of Woolf, in order that lower confidence limits larger than 1.0 would correspond to a one-sided $p$ value $<0.05$.

For each symptom, adjusted oRs for each ventilation type were calculated using a separate unconditional logistic regression model with the symptom as a dichotomous dependent variable. Independent variables were represented with dichotomous indicator variables for each stratum. Two terms for ventilation category -- mechanically ventilated and airconditioned -- were included in the models, with naturally ventilated buildings as the reference level. Initial long models also contained other covariates, representing personal factors (gender, age, race, education, smoking), psychosocial factors (job stress, job dissatisfaction), job factors (job type, hours per week in building, use of carbonless copies, use of photocopiers, and use of computers), workspace factors (sharing of workspace wth 
other workers, cloth partitions, carpets, new carpets, new walls, new paint, distance from a window, ability to see out a window, and amount of natural light), and problem building status. These were factors found to be related to symptom reporting, either in previous studies or through bivariate analyses in this study.

Building age and size were not include in the multivariate model, as neither was associated with symptom prevalence in bivariate analyses after stratification for problem building status. Other variables omitted from the final model because of lack of bivariate associations with symptom prevalence included visual privacy at the workstation, laser printer near the workstation, photocopier near the workstation, and years working in the building. In addition to the set of long models, shorter models were created using a reverse stepwise regression algorithm. For each symptom model, terms for ventilation type, problem building status, personal factors, psychosocial factors, and job type were retained; other terms were retained only if they contributed significantly to the model $(p<0.05)$. Missing values of covariates for any respondent were imputed in all models by assigning the modal value for each variable within that respondent's building.

\section{RESULTS}

Response rate among eligible workers was $85 \%$ overall, with 880 completed questionnaires received from eligible 
workers. Building-specific response rates (shown in table 1) ranged from $76 \%$ to $97 \%$. Most reasons provided for worker nonparticipation involved lack of time.

Information about study participants is provided in table 3. Participants were predominantly female (71.1\%) and there were more workers in the clerical category (43.6\%) than in any other single job category. The proportion of smokers was low in all ventilation categories: only 18\% overall were current smokers, with the lowest proportions in the naturally ventilated buildings.

Table 2 shows crude (i.e., unadjusted for potential confounders) prevalence of work-related symptoms and symptom groups for the total study population (symptom groups analyzed are in bold type). Among the symptom groups, eye, nose, or throat symptoms $(40.3 \%)$ were the most common and chills or fever were the least common (4.5\%).

Figure 1 shows crude prevalence of work-related symptom groups (hereafter called symptoms) by ventilation type. Symptom prevalences were generally lowest within naturally ventilated buildings and highest within air-conditioned buildings. Prevalences of non-indoor air related symptoms, however, were similar in all ventilation types.

Table 4 shows, for seven work-related symptoms, crude ORs for workers in mechanically ventilated and in airconditioned buildings, relative to naturally ventilated buildings. For both mechanically ventilated and for all air-conditioned bui?dings, some elevation in crude oRs was 
apparent for all symptoms hypothesized to be related to indoor air, although oRs were consistently higher in the latter buildings. The highest oRs within both these . ventilation types were for dry or itchy skin, followed by chest tightness or difficulty breathing, and chills or fever. Eye, nose, or throat symptoms, fatigue or sleepiness, and headache were also somewhat elevated for both these ventilation types. No associations were seen for non-indoor air related symptoms.

For workers in air-conditioned buildings excluding the problem building, ORs were still elevated for all symptoms except the non-indoor air related, though the magnitude of the ORs was very similar to those for workers in the mechanically ventilated buildings.

Adjusted ORs (from the logistic regression models produced by reverse stepwide regression) are shown in table 5. Adjusted ORs were similar within the mechanically ventilated and air-conditioned buildings, with the highest ORs in both building groups again associated with skin symptoms, chest tightness or difficulty breathing, and chills or fever. In both, there was some elevation for fatigue or sleepiness, less for eye, nose, or throat symptoms, and none for headache. Non-indoor air related symptoms showed little increase.

Estimates from a set of long models containing terms only for personal and psychosocial factors, job type, and problem building status were very similar to those from the 
long models described above -- relationships remained essentially unchanged, although magnitude of some estimates varied.

\section{DI8C088ION}

This study has found higher prevalence of a number of work-related symptoms among workers in buildings with mechanical ventilation supply and exhaust, with or without air-conditioning. Presence or lack of operable windows do not explain these findings, as all mechanically ventilated buildings had operable windows. Humidification systems were not present in any study buildings.

Most symptom increases found in this study persisted after adjustment in a multivariate model for a variety of factors, although elevations in the crude ORs for headache were eliminated by adjustment. Some adjusted ORs within mechanically ventilated and air-conditioned buildings were striking: for skin symptoms, 5.0 and 5.6 ; for tight chest or difficulty breathing, 3.6 and 4.3 .

Comparable data from other studies is limited, because most similar studies, of multiple buildings selected without regard to worker complaints, did not use equally specific ventilation categories, and those which did reported only crude, and not adjusted, ORs. To the extent that these comparisons were possible, our findings are generally in agreement with those from other studies performed in different geographic locations. 
Crude ORs for workers within air-conditioned buildings in this study can be compared to crude oRs within airconditioned buildings without humidification in three European studies (15-17), using data from a published reanalysis (44), and with an additional study (51) by reanalyzing data supplied by the study author. ORs in this study for eye, nose, and throat symptoms, fatigue or sleepiness, and headache were within the range found in the European studies, while oRs in this study for tight chest or difficulty breathing, chills or fever, and skin symptoms were higher. These comparisons were unchanged by exclusion of the problem building data from this study.

crude oRs within mechanically ventilated buildings in this study could be compared with only one European study (51), again by reanalyzing data supplied by the study author. That study contained a category of buildings with mechanical supply ventilation and exhaust, without humidification. Increases in ORs in the other study were very similar, except that, again, ORs in this study for skin symptoms were higher. Three other studies $(17,20,22)$ had included mechanically ventilated buildings, but had not distinguished buildings with mechanical exhaust only from those with mechanical supply and exhaust in their reports of crude prevalence. These studies found no increased symptom prevalence in the groups of buildings with mechanical ventilation. Later multivariate analyses (52) by authors of an earlier study (22) did distinguish these two types of 
mechanical ventilation, but combined them with other ventilation types. They reported higher symptom prevalences within buildings with mechanical supply and exhaust than. within buildings with mechanical exhaust only or natural ventilation. Interpretation of this finding is difficult because the former category included one building with airconditioning and humidification, which had the highest symptom prevalence of any building in the study.

possible explanations for lindings. One possible explanation for the findings of this and other crosssectional studies of workers in buildings of different ventilation types would be that mechanical ventilation systems are associated with poor thermal comfort. Available data do not support such an association $(14,23,17)$. Another explanation would be that mechanical ventilation systems are associated with the production, amplification, or dissemination in ventilation systems of contaminants, either biological or chemical, that are related to occupant illness through as yet uncharacterized mechanisms. This is not a new idea (cf. 17, 27, 6, 44) but these California data provide additional indirect support for it.

Measures of environmental contaminants have not been included in many cross-sectional studies of office buildings and, even when included, have often been rudimentary. To date, however, studies have not associated increases in specific environmental contaminants with ventilation systems. Some studies, in fact, have found the opposite 
$(53,54)$. A small British study found higher concentrations within an air-conditioned building than in a naturally ventilated building of formaldehyde, volatile organic compounds, and respirable particulates $(66)$. Molhave and Thorsen reported that the primary source for vocs in a building studied was the ventilation system itself (65). Among specific measured environmental parameters, temperature is the one most consistently found associated with prevalence of work-related symptoms $(57,63,64)$. Specific measured contaminants have usually not been found associated with increased symptom prevalence among office workers, in problem building investigations where such comparisons were reported (47), and in cross--sectional studies $(14,54,52,66,30)$. There have been a number of exceptions, however. In a Danish study, concentrations of dust of biologic origin was related to increases in mucous membrane irritation symptoms, and in headache, lethargy, or malaise (52). In a British study, levels of airborne viable fungi were associated with blocked nose, dry throat, and dry skin among buildings of each ventilation type, even though naturally ventilated buildings had the lowest symptom prevalence and the highest concentration of fungi (53). In a U.S. study, personal area levels of volatile organics and light intensity were associated with symptom prevalence (60). Controlled studies by Molhave (58) and otto (59) have demonstrated SBS symptom increases from exposures to low levels of mixed vocs. 
Because space sharing or larger number of workers in a total workplace have been associated in some studies with increased symptoms $(60,52,73)$, mechanical ventilation . systems which recirculate air may increase the effective sharing of space for workers. The effect might be from increased pollutant generation or from increased exposure to airborne infectious agents from others. Brundage, in an exceptionally well-controlled study among U.S. army recruits, found increases in febrile infectious pulmonary disease among occupants of new, tight barracks with recirculated air compared to recruits in older, naturally ventilated barracks (39).

Associations of symptom prevalence with general environmental factors, as surrogates for specific exposures, have also been assessed in some prior studies. Low fresh air ventilation rates (as a proxy for higher concentration of indoor-produced pollutants), elevated concentrations of total volatile organic compounds, and high or low humidity, have not correlated with symptoms $(14,16,54)$. An exception is a recent study from sweden in which lower ventilation rates were associated with prevalence of general symptoms (62).

Symptom prevalence has been associated with a number of other features of buildings or workspaces, at least in individual studies: air-conditioning fan-coil or induction units $(15,19)$; central humidification systems $(15,19,44)$; presence of carpets, cloth-covered surfaces, or open 
shelving $(52,56)$; building cleanliness $(52,57,76)$; and quality of ventilation system maintenance (54).

Frequent reports of dry, stuffy, or stale air in complaint episodes has led to a widespread belief that inadequate fresh air ventilation in tight buildings was responsible for the emergence of the SBS phenomenon, as occupant perceptions have often been considered a surrogate for actual measures of conditions. Increasing evidence now exists that, at least for some factors, perceptions may more appropriately be considered outcome factors. For instance, in a number of studies, complaints among office workers of dry air have been associated with symptom prevalence and not at all with measured relative humidity $(62,54,81)$. The sensation of dry stuffy air may thus be hypothesized to result from a physiologic response to particular indoor contaminants. Findings of a recent experimental study may demonstrate this: workers whose carpets and fabric furnishings were intensively cleaned, without their knowledge, resulting in lower levels of dust mites and presumably other contaminants as well, reported not only fewer symptoms relative to workers in spaces not cleaned, but also reductions in stuffiness, smelliness of air, and dissatisfaction with air quality and temperature (76).

Iimits to interpretation. This is the first study reported from the U.S. of office workers within buildings of different ventilation type, selected from a defined building population without regard to worker complaints. Because the 
study was small and included only workers from public office buildings from a limited geographic area, the results cannot be assumed representative of U.S. office buildings. Our. findings may not apply to workers in buildings in the private sector, or in different climate zones, or with different ventilation system configurations. The generally similar findings from comparable studies make our findings plausible, but other, larger studies in the U.S. will be necessary for confirmation.

These findings should also be interpreted cautiously, given the potential biases that may have influenced them. The most prominent potential biases relate to selection, response, and confounding.

Careful enumeration of all eligible buildings minimized bias in selection of buildings. Access to the eligible naturally and mechanically ventilated buildings was reasonably good, but the high refusal rate encountered for air-conditioned buildings specifically because of existing environmental dissatisfaction may have resulted in an underestimate of symptom prevalence within air-conditioned buildings in our target population.

Selection bias at the individual worker level may also have resulted in an underestimation of any actual associations, if workers with building-related health problems either had left work in their buildings or were absent through illness more often than others. Such a bias is likely to have been minimal, although no data are 
available on the frequency and severity of buildingassociated health problems.

If workers over-interpreting their symptoms as workrelated were more likely to complete a questionnaire, then effect estimates could be biased upwards for ventilation types in which this skewed response occurred. That response rates were high, and similar, within all ventilation types (828 in natural, 848 in mechanical, and $86 \%$ in airconditioned buildings) makes substantial bias of this type unlikely. This conclusion is further supported by the fact that response was $81 \%$ in the problem building, though it had the highest symptom prevalence.

Some potential confounding factors were minimized in the study design and others controlled in the analysis. Although residual confounding may have remained, adjustment even for two levels of a confounder controls most of the confounding effect [77].

In theory, other confounders not considered here could explain our findings; however, these would have to be strongly related to both symptoms and ventilation type. Building size and building age might be such factors, as both were found in a previous study to be associated with symptom prevalence (52), and are often associated with ventilation type. These factors, however, are likely surrogates for specific exposure factors. It is difficult to estimate effects of these two factors independently from those of ventilation type in our small study, particularly 
since all the newest buildings were air-conditioned, and the oldest naturally ventilated. Neither factor was found to be related to symptoms in bivariate analyses. Nevertheless,. because the newest buildings in our study were 3,8 , and 12 years old, the study provides no evidence about higher symptom prevalence (suggested anecdotally) in buildings only one or two years old.

Another potential confuunding factor in this study is worker concern about health effects of indoor air quality (which could also be considered a reporting bias). Concerns associated more with a particular ventilation type might, through hyper-vigilance or enhanced recall, upwardly bias estimates of symptom prevalence for workers within that ventilation type. Such over-reporting is an important potential bias in studies of SBS without objective health measures.

It is possible in our data to assess such overreporting in several ways. First, our study assessed prevalence of several symptoms hypothesized to be unrelated to indoor air or ventilation type: toothache, earache, and neck or shoulder pain. The combined prevalence of these symptoms, considered as an index of over-reporting, was not elevated in mechanical or air-conditioned buildings, although most other symptoms assessed were elevated. This finding is not consistent with general symptom overreporting as an explanation for the associations found in our study. A limitation of the index is that, because 
prevalence of earache and toothache were low (see table 2), the over-reporting index mostly reflects prevalence of neck or shoulder pain.

Second, over-reporting of specific symptoms often connected in the news media with indoor air problems does not provide a plausible explanation for associations found, because such symptoms as eye, nose, and throat symptoms, fatigue, and headache did not show the highest ventilation type-associated increases. These occurred in skin and lower respiratory symptoms. Furthermore, as media reports have usually involved newer air-conditioned buildings with sealed windows (hence the alternative name for sick building syndrome, "tight building syndrome") a priori worker health concerns would be likely to center on this type of building. Because symptom increases in our study were equally high within the older mechanically ventilated buildings with operable windows and the newer, sealed air-conditioned buildings, worker concerns regarding their type of ventilation are not a likely explanation for our findings. Third, symptom reports from workers within a problem building would be particularly susceptible to over-reporting bias. Yet the OR for non-indoor air related symptoms within the problem building was 1.4 (relative to 1.0 in the other air-conditioned buildings), suggesting only a moderate amount of over-reporting even in this building. This was controlled for by inclusion of a problem building term in all multivariate models. 
We cannot identify biases likely to explain our findings. If the consistent findings from this and other cross-sectional studies of office workers are not due to. bias, then air conditioning and possibly mechanical ventilation supply are risk factors for increased worker symptoms.

suggested research. Further research, in the U.S. and elsewhere, is needed to identify exposures or other factors responsible for currently ill-defined building-associated illnesses. As the set of possible exposures to measure is almost unlimited, research should focus on potential indicators of problem exposures -- such as the environmental factors found to be correlated with symptoms -- and move toward increasingly precise indicators of specific exposures. The development of preliminary case definitions for building-associated illness syndromes not yet characterized would help focus this search for causal exposures, as would development of relevant objective health measures.

Relationships found in this and in European studies suggest a possibly substantial preventable health problem among the large population of U.S. office workers. Resulting costs, for health care and through losses in time and productivity, may be substantial (55). We must eventually ascertain whether features of modern building design, construction, and maintenance are causally related to occupant health effects, and if so, learn how to create 
more healthy building environments in which to live and work. 
TABLE 1. Descriptive information on northem Califomia office buildings, June-September, 1990.

\begin{tabular}{|c|c|c|c|c|c|c|c|}
\hline Ventilation Type & $\begin{array}{l}\text { Building } \\
\text { Number }\end{array}$ & $\begin{array}{c}\text { Building } \\
\text { Size } \\
\text { (2q m) } \\
\end{array}$ & $\begin{array}{l}\text { Number } \\
\text { Foors in } \\
\text { Building }\end{array}$ & $\begin{array}{l}\text { Year } \\
\text { Built } \\
\end{array}$ & $\begin{array}{l}\text { Total no. } \\
\text { Eligibie } \\
\text { Workers }\end{array}$ & $\begin{array}{c}\text { Question- } \\
\text { naires } \\
\text { Received } \\
\end{array}$ & $\begin{array}{c}\text { Respo } \\
\text { Rate } \\
\end{array}$ \\
\hline \multirow[t]{3}{*}{ natural } & 1 & 3,620 & 10 & $1964^{\circ}$ & 54 & 41 & $76 \%$ \\
\hline & 10 & 2,320 & 3 & 1895 & 35 & 34 & $97 \%$ \\
\hline & 12 & $47,940^{+}$ & 6 & 1915 & 69 & 55 & $80 \%$ \\
\hline \multirow[t]{3}{*}{ simple mechanical } & 6 & 6,320 & 2 & 1955 & 44 & 41 & $93 \%$ \\
\hline & 9 & 2,320 & 4 & 1954 & 59 & 50 & $85 \%$ \\
\hline & 11 & $47,940^{+}$ & 6 & 1915 & 99 & 79 & $80 \%$ \\
\hline \multirow[t]{6}{*}{ air-conditioned } & $2^{+\infty}$ & 15,890 & 9 & 1978 & 186 & 151 & $81 \%$ \\
\hline & 3 & 19,510 & 7 & 1982 & 113 & 96 & $85 \%$ \\
\hline & 7 & 8,640 & 5 & 1964 & 106 & 89 & $84 \%$ \\
\hline & 8 & 8,360 & 4 & 1964 & 97 & 83 & $86 \%$ \\
\hline & 4 & 3,620 & 3 & 1987 & 117 & 111 & $95 \%$ \\
\hline & 5 & 8,360 & 12 & 1957 & 53 & 50 & $94 \%$ \\
\hline Total, 12 buildings & & & & & 1032 & 880 & $85 \%$ \\
\hline
\end{tabular}

- date building totally rebuilt within; originally constructed in 1912

- buildings 11 and 12 were spaces of 1,300 and $1,020 \mathrm{sq}$. m. located within a sinjle large building

- known problem building 
TABLE 2. Prevalence of work-related symptoms in study population + of workers in northern California office buildings, June-Sef.ember, 1990

\begin{tabular}{|c|c|c|c|}
\hline \multicolumn{2}{|c|}{$\begin{array}{l}\text { hypothesized to be related } \\
\text { to indoor air quality }\end{array}$} & \multicolumn{2}{|c|}{$\begin{array}{l}\text { hypothesized to be unrelated } \\
\text { to indoor air quality }\end{array}$} \\
\hline symptoms & $\begin{array}{c}\text { prevalence } \\
(\%)\end{array}$ & symptoms & $\begin{array}{l}\text { prevalence } \\
(\%)\end{array}$ \\
\hline $\begin{array}{l}\text { Eye, Nose, or Throat } \\
\text { Symptoms' } \\
\text { runny nose } 2 \\
\text { stuffy nose } \\
\text { dry irritated throat }{ }^{2} \\
\text { dry, irritated, or } \\
\text { itching eyes }\end{array}$ & $\begin{array}{l}40.3 \\
16.6 \\
25.2 \\
17.7 \\
\\
22.0\end{array}$ & $\begin{array}{l}\text { Non-Indoor Air } \\
\text { Related } \\
\text { earache } \\
\text { toothache } \\
\text { shoulder pain or } \\
\text { numbness }{ }^{2}\end{array}$ & $\begin{array}{l}15.3 \\
2.7 \\
1.0 \\
14.1\end{array}$ \\
\hline $\begin{array}{l}\text { Chest Tightness or } \\
\text { Difficulty Breathing' } \\
\text { chest tightness }{ }^{2} \\
\text { difficulty breathing }\end{array}$ & $\begin{array}{l}7.5 \\
3.7 \\
6.5\end{array}$ & & \\
\hline Chills or Fever ${ }^{1,2}$ & 4.5 & & \\
\hline $\begin{array}{l}\text { Fatigue or Sleepiness } 1 \\
\text { fatigue/tiredness }{ }^{2} \\
\text { sleepiness }\end{array}$ & $\begin{array}{l}33.2 \\
25.4 \\
24.9\end{array}$ & & \\
\hline Headache 1.2 & 19.8 & & \\
\hline Dry or Itchy Skin 1,2 & 10.8 & & \\
\hline
\end{tabular}


TABLE 3. Distribution of individual characteristics within ventilation categories, and in total population of workers in northem California office buildings, June-September, 1990

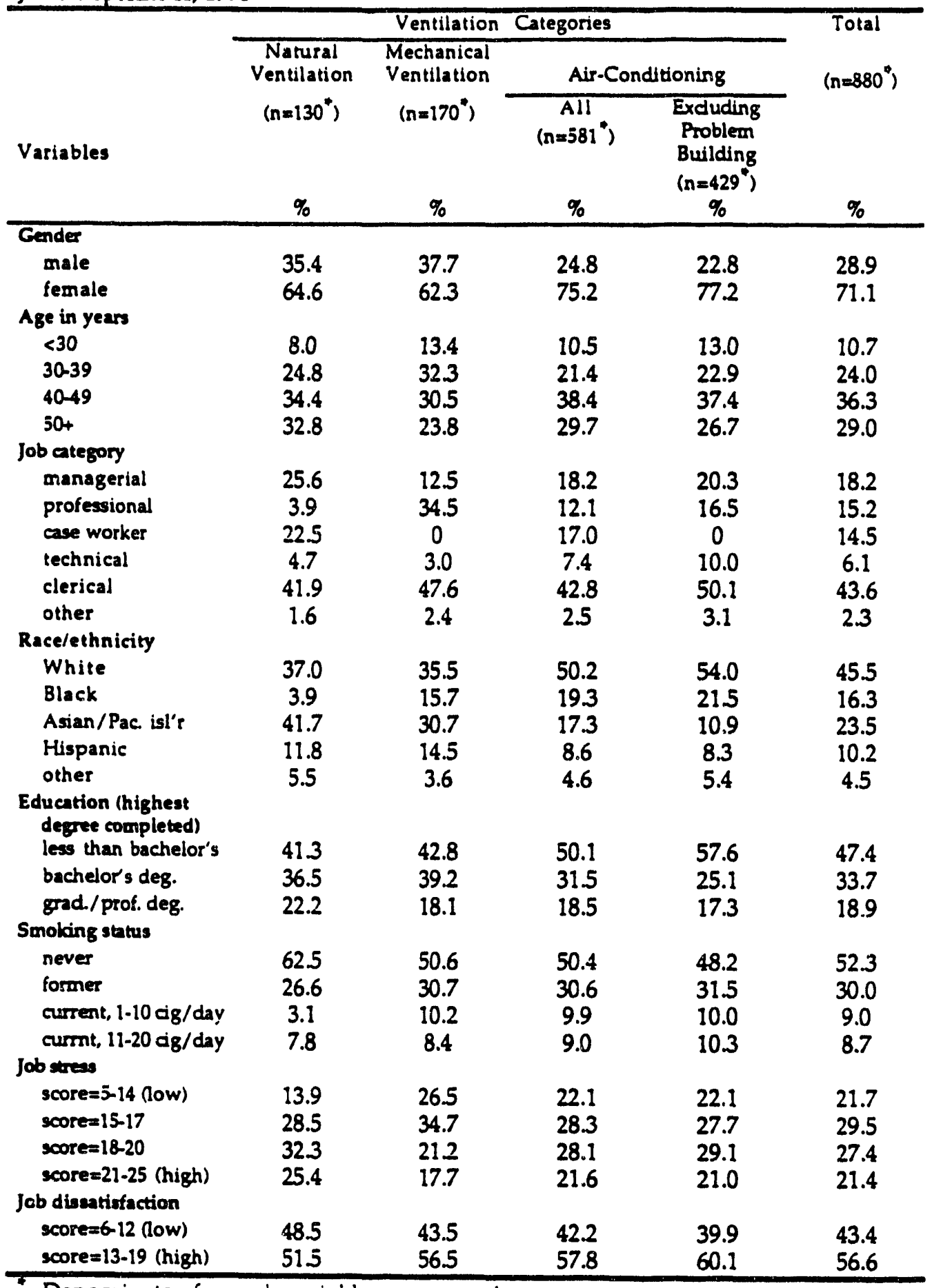

Denominator for each variable may vary due to non-response. 


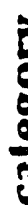
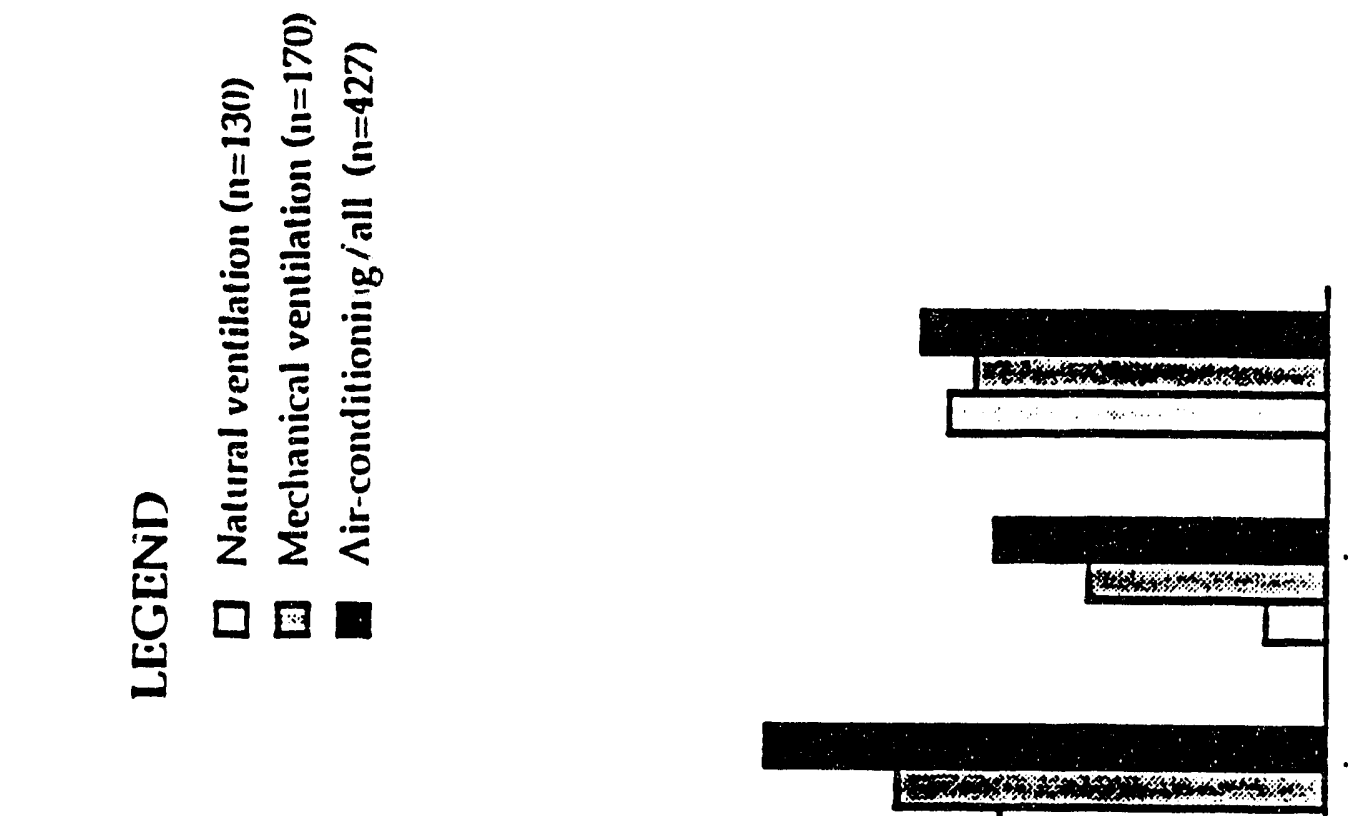

In

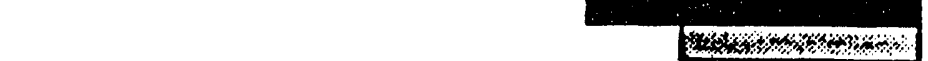

.

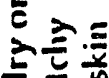

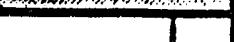

등

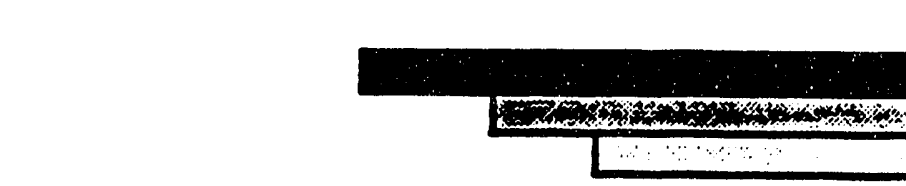




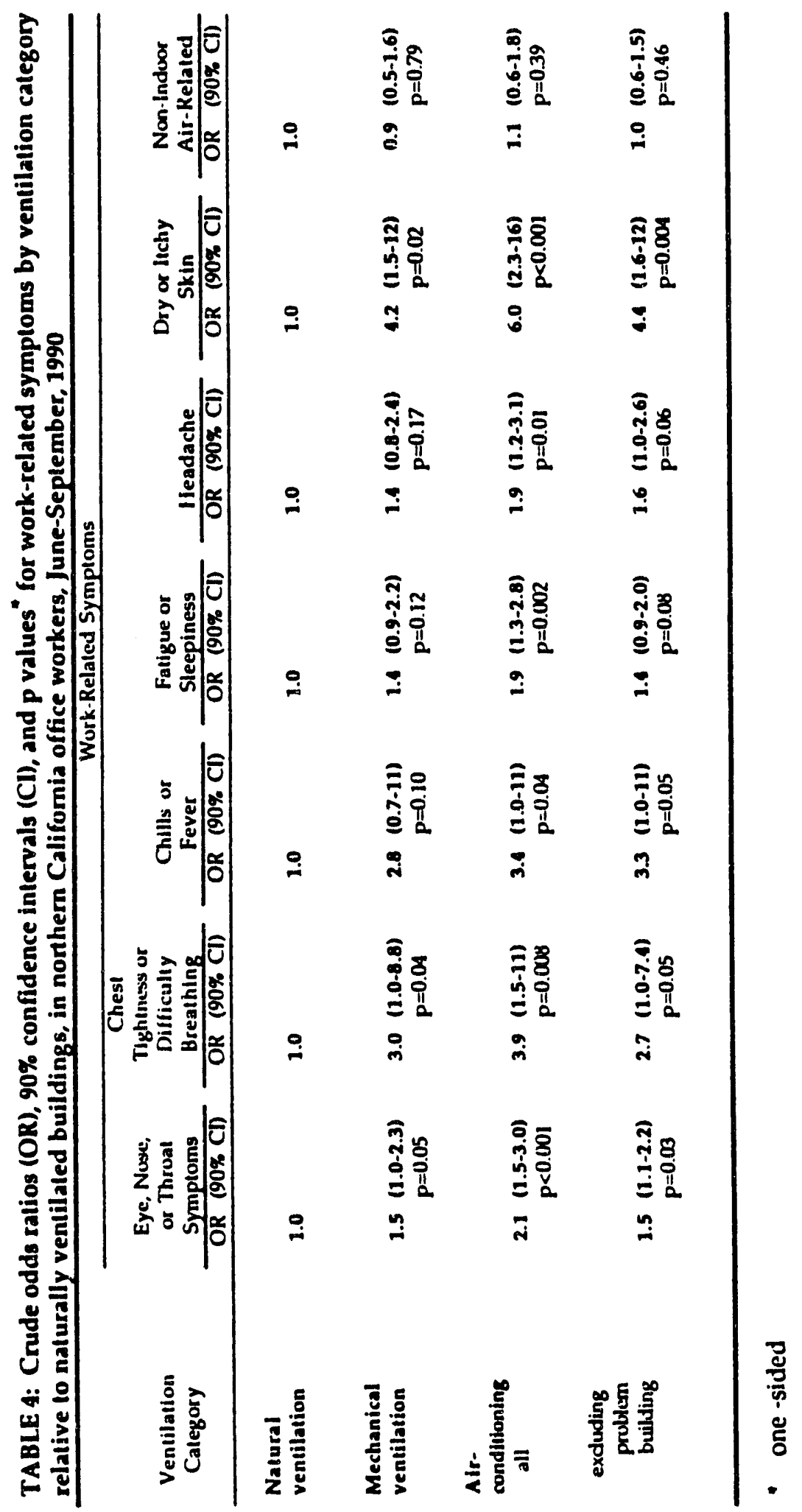




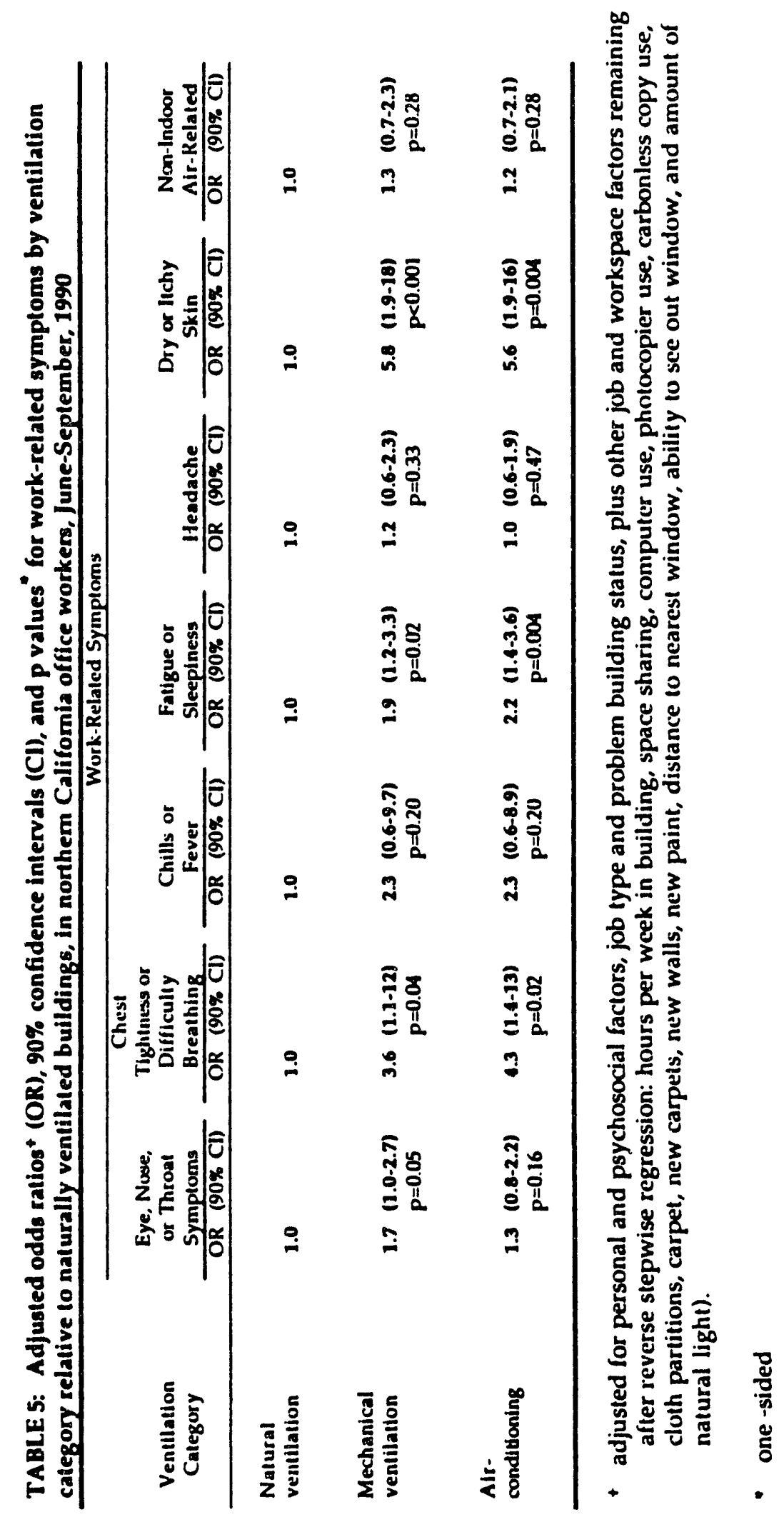


4. WORK-RELATED BYMPTOMB MYONG NORTHERN CAIIFORNIA OFPICE WORKERS: ABSOCIATIONB WITE PERSONAL, JOB, AND WORKBPACE FACTORS

Episodes of health complaints among office workers have been reported with increasing frequency during the last 20 years (1). Investigators have identified specific diseases or responsible exposures in some of these episodes, and these are collectively referred to as instances of "building-related illness" (30). In most, however, explanatory diseases or exposures have not been identified, and to these episodes the name "sick-building syndrome" (SBS) has been applied (46).

Early investigations of SBS, focused entirely on office buildings in which workers expressed numerous and severe complaints, suffered from problems of reporting bias and lack of comparison data (30). Also, the traditional industrial hygiene measurements and industrial workplace standards were of limited usefulness in identifying causal factors.

More recent cross-sectional studies in Europe, of workers in office buildings selected without regard to worker complaints, have avoided many of the problems of earlier investigations. These studies $(15-17,20-22,50,66$; reviewed in 30,44 ; $M J M$, unpublished analyses of data from 51) have provided increasing evidence that a consistent set of acute health complaints among office workers may be caused by as yet unidentified environmental factors in 
buildings (even if such complaints may be also influenced by psychosocial or other factors.)

In cross-sectional studies thus far, the most consistent findings have been of relationships between elevated symptom prevalence in offices and a variety of factors which are likely surrogates of exposure, such as air-conditioning and humidification systems (44), or carpets (52). In these studies, as in most investigations of problem building episodes, symptom reports have rarely been associated with any environmental contaminants at levels above existing standards $(4,6)$. Some recent studies have suggested relationships between office worker symptoms and exposures below existing standards $(58,59,56,60)$. The exposures relevant to this problem thus may not be adequately assessed by current measurement approaches or controlled by existing standards.

Because of limits in the research reported to date in the U.S., it has not been evident whether the problems suggested in European studies also exist in the U.S. Thus, the initial goal of this study was to attempt confirmation of European findings in a population of U.S. office workers, beginning with the nonspecific symptoms and general environmental factors found consistently related to each other in European studies. A previous paper reported our findings, in our study of California office workers, of increased office worker symptoms within air-conditioned buildings relative to naturally ventilated buildings (100), 
as had been found in all published European studies (44). We also found increased worker symptoms within buildings with mechanical supply ventilation but no air-conditioning, a finding consistent with the few comparable studies available (100). Our findings reflected adjustment for numerous personal, job, and workspace factors, and seemed unlikely to be explained by a number of possible biases. We report here the findings, in our study of California office workers, on associations between work-related symptoms and a number of job and workspace factors. We hypothesized, based in part on previously reported findings, that factors such as type of job $(19,23)$, use of carbonless copies or photocopiers (23), presence of carpets or cloth partitions in the workplace (23), and sharing of workspace with others (68) would be associated with increased prevalence of work-related symptoms in office workers. We also explored whether symptom increases were associated with other factors, including: new carpets, new paint, or new construction, use of video display terminals (vdts), distance from a window, lack of natural light, and inability to see out a window.

\section{MATERIALS AND METHODS}

\section{study design and population}

The study design and methods have been reported in detail elsewhere $(45,100)$. We studied workers within public office buildings of three different ventilation types, 
within a limited geographic area in northern California, between June and September of 1990. Building selection was based upon an assembled list of city and county owned office buildings in the San Francisco Bay Area, which was narrowed to include only buildings meeting the following criteria: located in San Francisco, Contra Costa, or western Alameda Counties; containing more than 10,000 square feet of currently occupied office space, occupied by at least 45 full-time office workers (including at least 10 clerical workers); not containing unusual pollutant sources, ongoing renovation, or large scale occupant relocations; and having one of three types of ventilation system:

1) natural ventilation with operable windows;

2) mechanical supply and exhaust ventilation with no ais conditioning and no humidification, and with operable windows; and

3) mechanical supply and exhaust ventilation with airconditioning and no humidification, and with sealed windows (built as non-operable). These are referred to below as: 1) naturally ventilated, 2) mechanically ventilated, and 3) air-conditioned.

We studied workers in the 12 buildings to which we were granted access, out of 19 eligible. These consisted of three naturally ventilated, three mechanically ventilated, and six air-conditioned buildings. Smoking within all buildings on our list was prohibited by building policy, except in small designated areas. 
Within each study building, we included workers from specific spaces rather than from the entire building. study spaces were selected so that the working environments . studied in different buildings would be as similar as possible. Where available, open office areas with 45 or more workers were selected, along with any adjoining enclosed offices. Where this was not possible, smaller spaces containing a total of at least 45 workers were combined.

Eligible workers were all those in the study spaces, excluding any who had worked in the building for less than three months, any who generally worked in the building for less than 20 hours per week, and any who were absent from the office for one week or more during our study period. Questionnaire

The questionnaire used in our study was a modified version of a self-administered questionnaire from a study of several U.S. Government buildings in Washington, D.C. (47). The questionnaire asked about the frequency of 15 symptoms occurring at work, during the previous week and also during the previous year, and whether each symptom changed when the respondent was not at work. The symptom question is included in Appendix 2. Other questions assessed various health, demographic, psycho-social, and work-related parameters.

Questionnaires were distributed to all workers in each selected space at the beginning of a work week, for return 
into locked boxes supplied in each study space. Workers not returning completed questionnaires or written refusals were recontacted up to three times by phone before they were. considered non-respondents.

Analytical mothods

For the analyses presented here, we defined a workrelated symptom as one reported to have occurred often or always when at work the previous year, and also to have improved when away from work. Symptom groups for analysis were formed by combining related symptoms, with reporting of at least one work-related symptom within a group considered a positive response for that group. Six groups (eye, nose, or throat symptoms: chest tightness or difficulty breathing; chills or fever: fatigue or sleepiness; headache; dry or itchy skin) were formed from 11 symptoms hypothesized, on the basis of previous reports, to be related to indoor air factors and ventilation type. An additional symptom group, not discussed in this paper, included symptoms not hypothesized to be related to indoor air quality and ventilation type.

Analyses were performed using the statistical packages SAS 6.06 (48) and BMDP/90 (49). This paper will focus on associations between work-related symptoms and a number of job and workplace factors. Job factors included type of job, hours per week in the building, and use of carbonless copies, photocopiers, or vdts. Workspace factors included degree of workspace sharing with others, presence of carpet 
or of cloth partitions within the study space, amount of natural light, ability to see out of a window, and location near the workstation of either a window, new walls, new. paint, or new carpet. (Location near the workstation was defined as within fifteen feet, and "new" for carpets, paint, or walls was defined as new within the previous year. The question about new walls asked specifically about "walls rearranged or moved".)

Personal, psycho-social, and building factors were considered potential confounders and controlled in the analysis. Personal and psycho-social factors included gender, age, race/ethnicity, education, smoking status, job stress, and job satisfaction. Building factors included type of ventilation in the building, as well as whether the building was thought to be a "problem" building. (Building age and size, which were not associated with symptoms in bivariate analyses after stratification for problem building status, were not included in the final multivariate models.) Crude odds ratios (ORs) for associations between workrelated symptoms and potential risk factors were calculated using the Mantel-Haenszel estimate. For each symptom, adjusted ORs and $95 \%$ confidence intervals (CIs) for the effects of independent variables were also estimated, using a separate unconditional logistic regression model with the symptom as a dichotomous dependent variable. The initial long regression models contained terms for all independent variables listed in table 1 , represented by dichotomous 
Indicator variables for each stratum. A reverse stepwise regression algorithm was also used to produce a set of shorter models, as a check on possible over-parameterization in the long model. In the stepwise regression, a number of core variables (personal, psycho-social, and building factors, plus fob type) were retained in all models, and other terms were subject to removal by the stepwise algorithm if they did not contribute significantly to the model $(p<0.05)$.

Missing values for independent variables in all regression models were imputed for each respondent by assigning the modal value for each variable within the respondent's building.

\section{RESULTS}

Descriptive analysis

Response rate among eligible workers was $85 \%$ overall, with response rate for specific buildings ranging from 768 to 978 .

Table 1 provides information on distribution within the study population of factors considered in this analysis. Respondents were predominantly female and non-smokers, with the largest single groups being white, clerical workers, between 40 and 49 years of age, and working more than 30 hours a week. About half used computers more than an hour a day, with fewer using photocnpiers or carbonless copies this much. Most received at least a moderate amount of natural 
light at their workstations and could see out a window. Though most were also located near a window, the majority worked in air-conditioned buildings with sealed windows. About a quarter had many cloth-covered partitions in their study spaces, and about half had some carpets there, but very few had new carpets near their workstation. Bivariate analysis

Table 2 shows crude prevalence and ORs for work-related symptoms by potential risk factors. Three factors which had no evident relationship with any symptom in the multivariate models were omitted from this table, but retained in the model because of theoretical interest (hours per week in building, computer/vat use, and amount of natural light).

In the crude analysis, case workers had the highest symptom prevalences generally, followed by technical and clerical workers; professionals and managers had the lowest prevalence of symptoms. Job stress was strongly and positively related to all symptoms except chills or fever. Job dissatisfaction showed only a small, though consistent, association with increased symptoms.

Use of carbonless copies or of photocopiers, sharing of the workspace with two or more others, and lack of a window near the workstation were associated with increases in most symptoms. Inability to see out of a window was associated only with an increase in fatigue or sleepiness.

New paint near the workstation was associated with a decrease in prevalence of several symptoms Having cloth 
partitions within the study space was associated even more consistently with lower levels of symptom prevalence. Although carpet in the study space was associated with . slightly decreased prevalence of a number of symptoms, new carpet near the workstation was associated with increased prevalence of several symptoms, particularly for chest tightness of difficulty breathing.

\section{Multivariate analysis}

Adjusted ors from the set of long logistic regression models are shown in table 3. These were quite similar to ORs from the stepwise regression models, but showed patterns of association more clearly, due to the inclusion of estimates which did not achieve statistical significance. Estimates for the three variables omitted from table 2 were also omitted from this table.

Job factors. Technical, clerical, and case worker jobs were associated with increases in some work-related symptoms, most noticeably chills or fever, and skin symptoms.

Use of carbonless copies for more than one hour per day was associated with increases in almost all symptoms assessed; the highest oRs were for chest tightness or difficulty breathing, and fatigue or sleepiness, with statistically significant increases for these and for eye, nose, and throat symptoms. Use of photocopiers for more than one hour per day was associated with small increases in a number of symptoms, and with a substantial and significant 
increase in dry or itchy skin. Use of computers was not associated with altered prevalence of any symptom assessed (not shown).

Number of hours per week in the building was not associated with changes in symptom prevalence (not shown).

Workspace factors. Those sharing space with two or more others had increases in prevalence of chest tightness or difficulty breathing, fatigue or sleepiness, headache, and skin symptoms, the first three statistically significant. All other symptoms were slightly elevated.

Presence of any carpets in the study space was associated with increases in eye, nose, and throat symptoms, chest tightness or difficulty breathing, and headache, all statistically significant. There was also a strong association between new carpeting near the workstation and several symptoms: headache, eye, nose and throat symptoms, and chest tightness or difficulty breathing. The last two increases were statistically significant, with a particularly striking oR of 14.2 for the lower respiratory symptoms.

New walls were associated with some increase in all symptoms assessed, none statistically significant. New paint was associated with a reduced prevalence of all symptoms assessed, with reductions significant for eye, nose, and throat symptoms and fatigue or sleepiness. Cloth partitions were associated with even more consistently lower prevalence of all symptoms assessed, with reductions 
significant for eye, nose, and throat symptoms, chest tightness or difficulty breathing, and fatigue or sleepiness.

Lack of a window near the workstation was associated with an increase in all symptoms; the highest ORs, all statistically significant, were for chills or fever, headache, eye, nose, and throat symptoms, and fatigue or sleepiness. There was little association between symptom prevalence and either the ability to see outside a window or the amount of natural light at the workstation (not shown).

\section{DISCOSSION}

A number of job and workspace factors were found in this study, after multivariate adjustment, to be associated with work-related symptoms. Our findings thus confirm and extend findings by other researchers on relations between factors in the office environment and syraptoms commonly associated with the sick Building syndrome.

Job factors. Different job types in an office setting may represent differences in many factors, in addition to specific job activities, which are potentially related to symptom reporting; these include a variety of demographic, psychosocial, and workspace factors. The consistently high levels of symptoms actually reported by technical, clerical, and case workers were reduced quite substantially by multivariate adjustment for such other factors (a finding also reported by others (23)), which also showed independent 
associations with symptom prevalence. It is not known how much of the remaining multivariate adjusted associations between job type and symptom prevalence in this study is due to residual confounding by factors partially controlled for, and how much to effects of factors not assessed. Such factors include, for instance, exposures to office materials such as solvent-based correction fluid, or locations in particular types of office micro-environments. Findings in our study regarding specific job activities and work-related symptoms are generally but not entirely in agreement with previous reports. Specific symptoms elevated in this study among frequent users of carbonless copy paper are similar to those elevated in a Danish cross-sectional study -- they reported increased mucosal irritation (eye, nose, or throat symptoms) and general symptoms (headache, lethargy, or malaise) (23) -- and in case reports (e.g., 72), although we did not find the increases in skin symptoms reported by others. Available studies, although considered in a recent review to provide insufficient evidence for causality (68), have consistently linked exposures to carbonless copy forms to a similar set of symptom complaints. Our study design avoids many weaknesses of other studies cited in the review, such as a lack of unexposed subjects, failure to control for confounding factors, and a focus on workers who, blaming the carbonless copies they used for their health problems, were likely to over-report symptoms. 
Increases of symptoms among frequent users of photocopiers in this study are also in general agreement with previous reports from the Danish study (23); however, because that study did not report their data on skin symptoms, comparison with the high associated prevalence of skin symptoms found here was impossible.

Use of computers was not, in this study population, associated with increases in symptoms assessed, although associated increases in mucosal irritation were reported in the Danish study (23).

Hours per week spent in the building, as a variable roughly indexing length of exposure to any indoor environment factors, should show general associations with symptoms only in the presence of general indoor problem exposures. This variable was not in this study associated with symptom increases. In the Danish study, however, an increase in hours at work was associated with an increase in both mucosal irritation and general symptoms (23).

morkspace factors. Space sharing was consistently associated with increased prevalence of work-related symptoms. Such increases among those sharing space with two or more others may reflect confounding by some aspect of job type or demographics not fully controlled for in the model, increased exposure to worker generated pollutants, or enhanced transmission of infectious disease (although this last should not in fact cause symptoms which are experienced as temporaliy work-related). Another possibility is degree 
of visual privacy, but a dichotomous measure of this was not associated with symptom prevalence in our study, when added to the model in exploratory analyses.

There are a number of related previous findings. Hodgson et al. found that prevalence of central nervous system and eye, nose, and throat symptoms increased with the number of workers sharing a workspace (60). The Darish study found an increase in work-related general symptoms associated with either number of workplaces or total volume of space in the office, but not with area per employee, as well as an increase in mucosal irritation with total area of the office (52). Jaakkola found occurrence of colds to be more frequent among office workers sharing rooms (73). Both increased pollutant generation and increased disease transmission among larger numbers of workers in proximity would be consistent with these findings.

The association found in this study between presence of carpets in the workspace and increased symptoms may indicate exposure to bioaerosols or other particulate matter with an immunologic or irritant effect; it may also indicate chemical exposures, although this would be most likely with new carpets specifically. Carpeting has been associated in previous reports with elevated symptoms among office workers, either generally (52), when insufficiently cleaned (74), when containing irritant residues from improper shampooing (75), and even when known to be old, adequately vacuumed, and free of shampoo residue (56). Micro-organisms 
and potentially allergenic materials have been shown to accumulate in rugs and to be at higher concentrations in the air above rugs (56). The Danish study reported carpets to be associated with higher concentrations of organic dust, which was a strong independent risk factor for increased symptoms (52). Leinster et al. reported reduction in symptom prevalence among office workers whose carpets and fabric furnishings were thoroughly cleaned, relative to those in uncleaned spaces, when neither group had knowledge of the cleaning (76).

The strong association in our population between new carpets near the workstation and several work-related symptoms, particularly lower respiratory symptoms, seems more likely to indicate possible chemical exposures than bioaerosol or other particulate exposures. since a relatively small number of respondents (20) worked near new carpets, and this association has to our knowledge not been assessed or reported before, confirmation in other studies will be necessary. Anecdotally, new carpets are often among the most bothersome elements of new or remodelled indoor environments.

Association of cloth partitions in this study with a general and substantial decrease in symptom prevalence is puzzling. Preliminary analyses even suggested a dose response relation, but numbers were small and confidence intervals wide. This finding may indicate unidentified confounders, or some actual but unsuspected beneficent 
effect of partitions, perhaps due to ad- or absorption of chemicals, infectious agents, or noise. As we did not find a clear effect of visual privacy on symptom prevalence, this may not be the responsible factor here. Specific comparable data on this factor are not $\bigwedge^{\text {available. The Danish study }}$ reported increased symptoms associated with an index of "fleece factor," in which total area of cloth surfaces (carpets, curtains, wall coverings, and seat covers), was divided by volume of office space (52). Cloth covered partitions were not specifically mentioned as part of the index in published reports, and may not be included, but if they were, the index would not reveal different effects of carpets and cloth partitions.

We also know of no other reports associating new paint with a general decrease in symptoms, and assume unidentified confounders are the most likely explanation.

Because our questionnaire specifically asked about "new or rearranged walls", respondents identified in the data as near new walls may thus have been exposed to new construction materials and paint, or new movable partitions, or no new materials at all. The proper interpretation of this finding of increased symptom prevalence is thus not obvious, particularly as both paint and partitions were associated with lower symptom prevalence.

Lack of a window near the workstation was associated with an increase in all symptoms. We know of no othe: reports on this association. Presumably this finding could 
reflect residual confounding by job type or other elements of work status, or some physiological or psychological effect of natural light or view outside. We found, however, little multivariate adjusted association between symptoms and either the ability to see outside a window, or the amount of natural light at the workstation. Another possible explanation is an effect of being able to open a window, in buildings where it was possible. Because most workers in the naturally and mechanically ventilated buildings were near windows, all operable, while more workers in the air-conditioned buildings were not near windows, all of which were sealed, it was difficult in our data to disentangle these factors from each other. The model assumed an equal effect of proximity to windows across all building types, whether windows were operable or sealed. Exploratory analyses did suggest that distance from a window was less related to symptom prevalence when windows could not open (i.e., in the airconditioned buildings) than when they could (in the mechanically ventilated buildings); too few respondents in the naturally ventilated buildings were far from windows to make a similar comparison within these buildings.

We have earlier presented findings from this study, of higher work-related symptom prevalence among workers in buildings with mechanical ventilation or air-conditioning (in other words, with mechanical air supply, with or without air-conditioning or operable windows), after multivariate 
adjustment (100). Prevalence of a set of hypothetically "non-indoor air related" symptoms, however, did not differ by ventilation type. The findings of higher symptom . prevalence in air-conditioned buildings without humidification were consistent with all previously reported findings for buildings of this ventilation type -- only unadjusted estimates were available (15-17,44; reanalysis of data provided by author of 51). For the increases found in mechanically ventilated buildings without air-conditioning, few studies reported findings in truly comparable categories. Findings in one study (51) were found to be similar by reanalyzing unadjusted data obtained from the study author. In another study, multivariate adjusted increases in work-related symptom prevalence were found associated with mechanical supply and exhaust ventilation, relative to mechanical exhaust only or natural ventilation (52) .

\section{Limitations of study}

This is one of the first studies reported from the U.S. of office workers within buildings chosen without regard to worker complaints, and the first to study buildings of different ventilation type from a defined population of buildings. Because the study was small and included only workers from public office buildings of specific ventilation types in an area with limited geographic and climatic range, the results cannot be assumed representative of U.S. office buildings. Our findings may not apply to workers in 
buildings in the private sector, or in different climate zones, or with different ventilation system configurations. The general similarity of findings from other comparable' studies make our findings plausible, but other, larger studies in the U.S. Will be necessary to confirm and clarify them.

These findings should also be interpreted cautiously, given the potential biases that may have influenced them. The most prominent potential biases relate to selection, response, reporting, and confounding. Selection and response biases, considered in detail elsewhere (100), are likely to be minimal in this study. Confounding has been considered before (100) and in the discussion above. Possible reporting bias warrants caution because most of the data analyzed here were supplied by respondents, and their subjectively influenced reports may have produced distorted findings. As random, nondifferential errors would reduce the magnitude of actual associations assessed, perhaps the most misleading errors would be those arising from differential biases. These are most likely to arise in associations arousing strong respondent concerns, which in this study might include type of ventilation, lack of windows, inability to open a window, and strongly smelling substances like new carpets. It will be difficult to assess the extent of such biases, beyond what has already been attempted, until more objective measurements of exposures and health outcomes are developed. 
Poseible explanations for findings

If symptom associations found in this study with the job and workspace factors assessed were not due to differential reporting or confounding, then many of these factors are likely to be proxies for environmental exposures with adverse (or protective) effects. Of these factors, only carpet $(52,61)$ and ventilation systems $(65,67,78,79,80)$ have been thus far associated with specific measures of increased environmental contaminants or decreased indoor air quality.

other building factors not discussed herein have also been found to be associated with symptom prevalence at least in individual studies: air-conditioning fan-coil or induction units (17); central humidification systems $(15,19,44)$; open shelving $(52)$; building cleanliness $(52,57,76)$; and quality of ventilation system maintenance (54). For low fresh air ventilation rate (considered a proxy for higher concentration of indoor-produced pollutants), associations with symptom prevalence have not been found $(54,14,16)$ except in one recent study $(62)$.

Although most studies and complaint investjgations reported have not found measured contaminants or air quality parameters to be associated with increased symptom prevalence among office workers $(47,14,30,54,52,66)$, some such associations have been reported. Controlled studies have demonstrated increases in SBS symptoms $(58,59)$ and decreases in forced expiratory volume (FEV) (71) from 
exposures to low levels of mixed vocs. Symptom increases have in cross-sectional studies been associated with temperature $(57,63,64)$, light intensity $(60)$, concentrations of respirable dust (70), concentration of biologic dust (52), concentration of viable airborne fungi when compared within buildings of the same ventilation type (53), concentrations of vocs (70), and personal work area concentrations of vocs $(60)$. Symptom decreases in an office followed unannounced cleaning of carpets and fabric furnishings which reduced concentrations of dust mites (76). Most of these findings, however, have not been replicated. Research findings to date related to worker health problems in office buildings suggest a multifactorial phenomenon, occurring more widely than is currently appreciated. Three specific mechanisms seem potentially implicated. Volatile chemical compounds, likely to be particularly high in new, newly remodelled, or newly carpeted spaces, may be related to irritative symptoms (hypersensitivity pneumonitis from some synthetic chemicals is also possible $(30)$ ). Bioaerosols, growing on moist surfaces within building spaces or ventilation systems (particularly those inadequately cleaned or maintained), concentrated in buildings or spaces with inadequate fresh air ventilation, effectively disseminated by ventilation systems, and captured and re-released by high surface area materials might cause health problems by a number of mechanisms; exposures to these may lead to immune 
sensitization of susceptible individuals so that even low levels thereafter elicit responses $(30)$, or there may be a toxic or irritative response to micro-organisms or their ' products. And infectious agents, transmitted through indoor air or on indoor surfaces, may be increased in areas of increased occupant density or increased recirculation of ventilation air (39).

\section{suggested research}

This study has identified a number of job, workspace, and building factors associated, after multivariate adjustment, with increased prevalence of work-related symptoms. These results confirm and extend findings, mostly from other countries, about work-related symptoms and environmental factors in offices.

Further research, in the U.S. and exsewhere, is needed to corroborate these findings and to identify specific conditions or exposures responsiole for currently illdefined building-associated illnesses. The factors and symptoms associated in this and other studies may seem frustratingly imprecise, but they serve as potential indicators of specific causal exposures or conditions and specific building-related illnesses. The systematic identification of increasingly precise surrogates of exposure and indicators of disease will likely be necessary, given the almost unlimited number of measurements technologically possible. Development of new and appropriate environmental measurement techniques, relevant 
objective health measures, and case definitions of more specific building-associated illness syndromes will also be necessary.

Relationships found in this and in other studies, if confirmed, would suggest a substantial preventable acute health problem among the large population of U.S. office workers, and perhaps among occupants of other indoor environments with similar exposures or conditions. Related costs, for health care and from losses in time and productivity, would likeiy be substantial (55). Because so much of our time is spent indoors, it is important that we identify features of modern buildings which create illness or discomfort for occupants, so that we can create healthy building environments in which to live and work. 


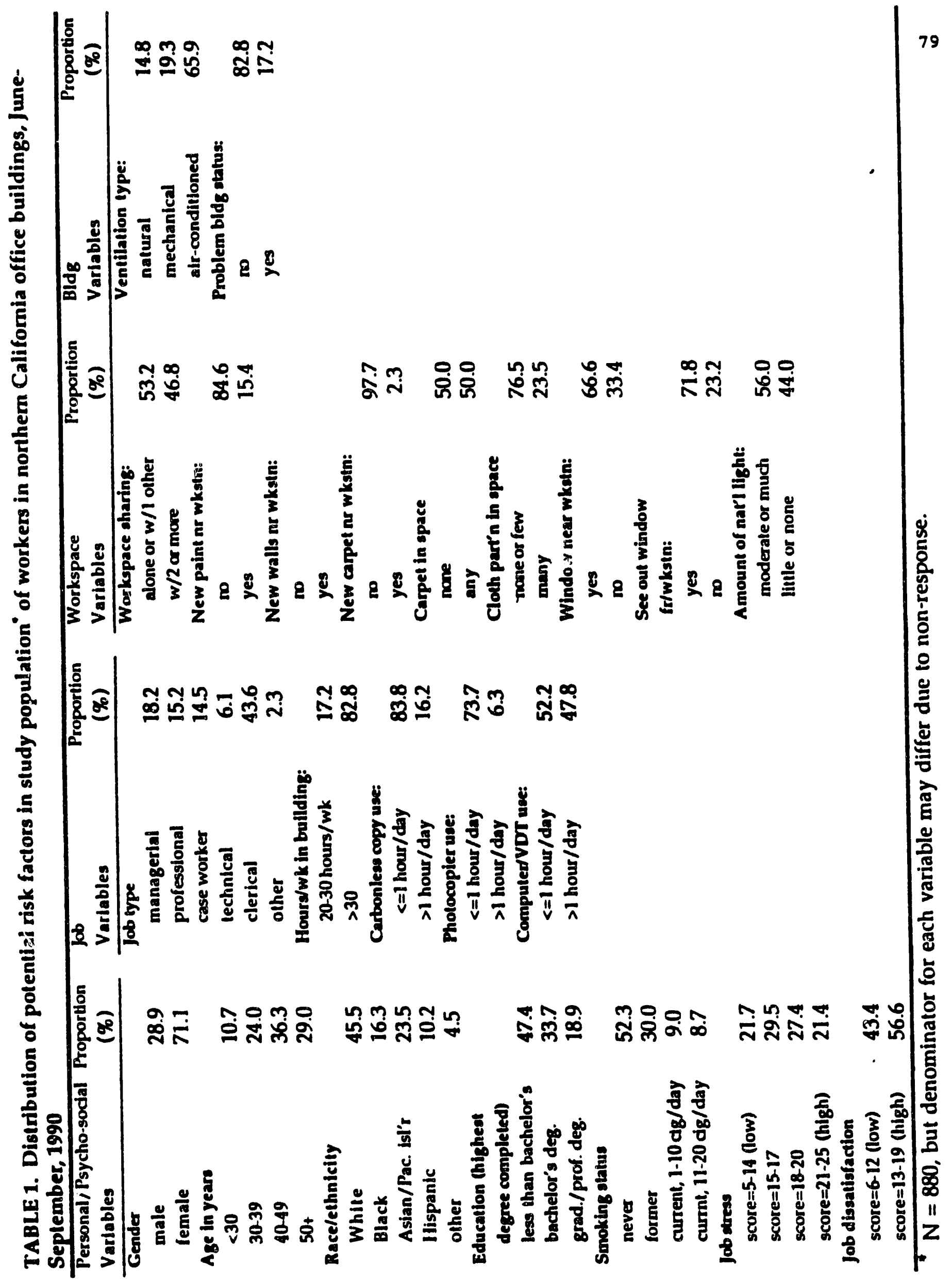




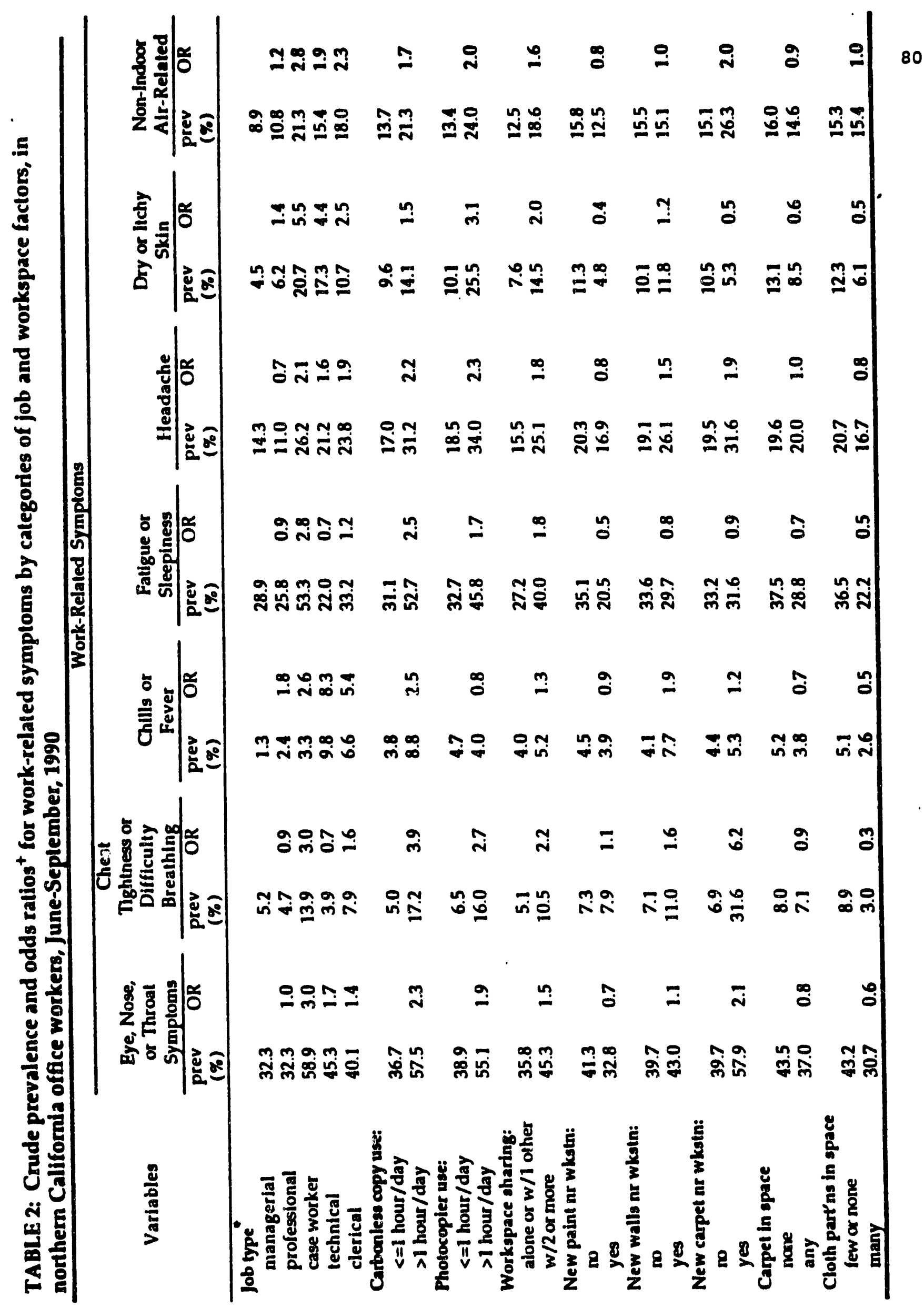




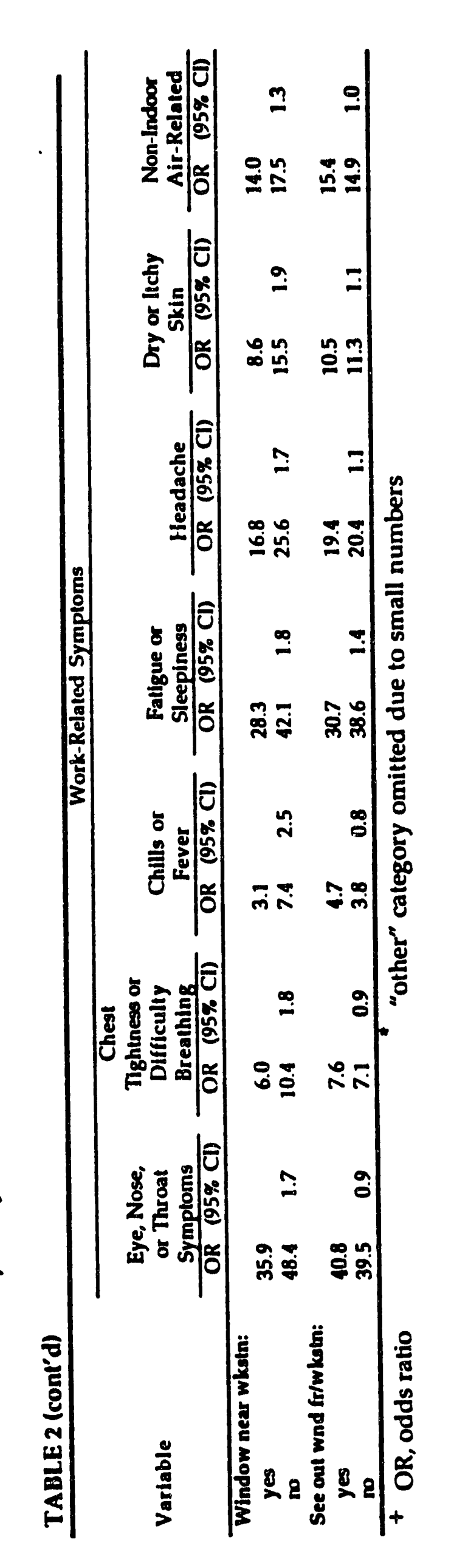




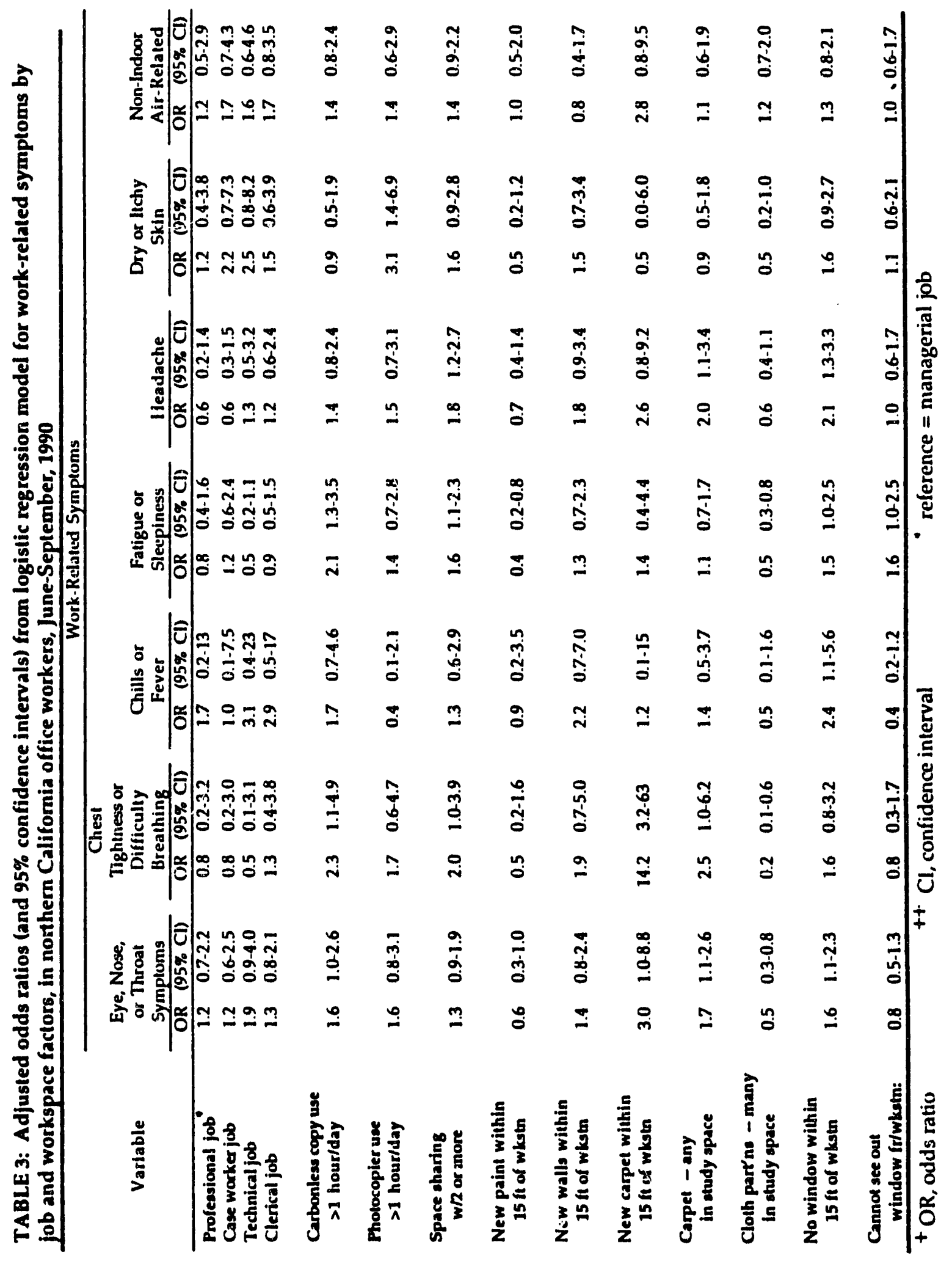




\section{POTORE REBEARCE ON ACOTB TORK-REIATED EEALTE PROBLEMS IN OPFICE WORTERS}

Findings from the reanalysis of previous studies . presented in Chapter 2, from a large Dutch study reanalyzed afterward (see table 1), and from the California study reported in chapters 3 and 4 , are all generally consistent. They suggest that a number of factors in office buildings are related to increases in symptom prevalence among the workers within, and that such symptom increases may be relatively common because the factors associated are common, but that specific causal exposures involved cannot be easily identified using current approaches. Furthermore, they suggest that SBS, although involving psychological factors, is not likely to be of purely psychologic origin.

Research is needed to confirm and extend these findings. As SBS and related unrecognized phenomena are likely multifactorial in origin, research needs to recognize chemical, biological, physical, and psychological aspects of the problem, although all research need not focus on all possible aspects.

Because it is not clear in this research what the relevant factors to measure are, it would be possible to spend an enormous amount of money with very little scientific return. There will be a temptation to perform large studies involving a great number of detailed measurements in many buildings, and then to see what correlates with what, under the assumption that if one 
measures everything, one is sure to find the critical factor. If past findings are any guide, such fishing expeditions may yield few useful associations. Furthermore, numerous misleading chance associations are likely to arise in such studies. It will be more efficient to perform initial inexpensive surveys of many buildings to identify those with highest and lowest associated symptom prevalence for more focused comparisons (in building-level case control studies), using existing as well as newly aeveloped techniques.

Development of new environmental measures must be guided by consideration of currently implicated surrogates of exposure and careful biologic reasoning, rather than simply by trying to measure everything in more detail. New objective measures of health status must also be developed to remove the health outcomes from the realm of the totally subjective. The identification of specific new indoor airrelated illness syndromes would facilitate these efforts. In public health, according to a recent article in the Journal of the American Medical Association, ". . the focus has shifted from the avoidance of clinical disease among highly exposed individuals toward the protection of the general population from an unacceptable burden of disease at much lower exposures, an attempt to ensure that even the most susceptible persons are not adversely affected (83)." This is particularly appropriate where substantial proportions of the population are involved. Because most of 
the population spends the great majority of its time indoors, it is essential that we create and maintajin healthy indoor environments. 


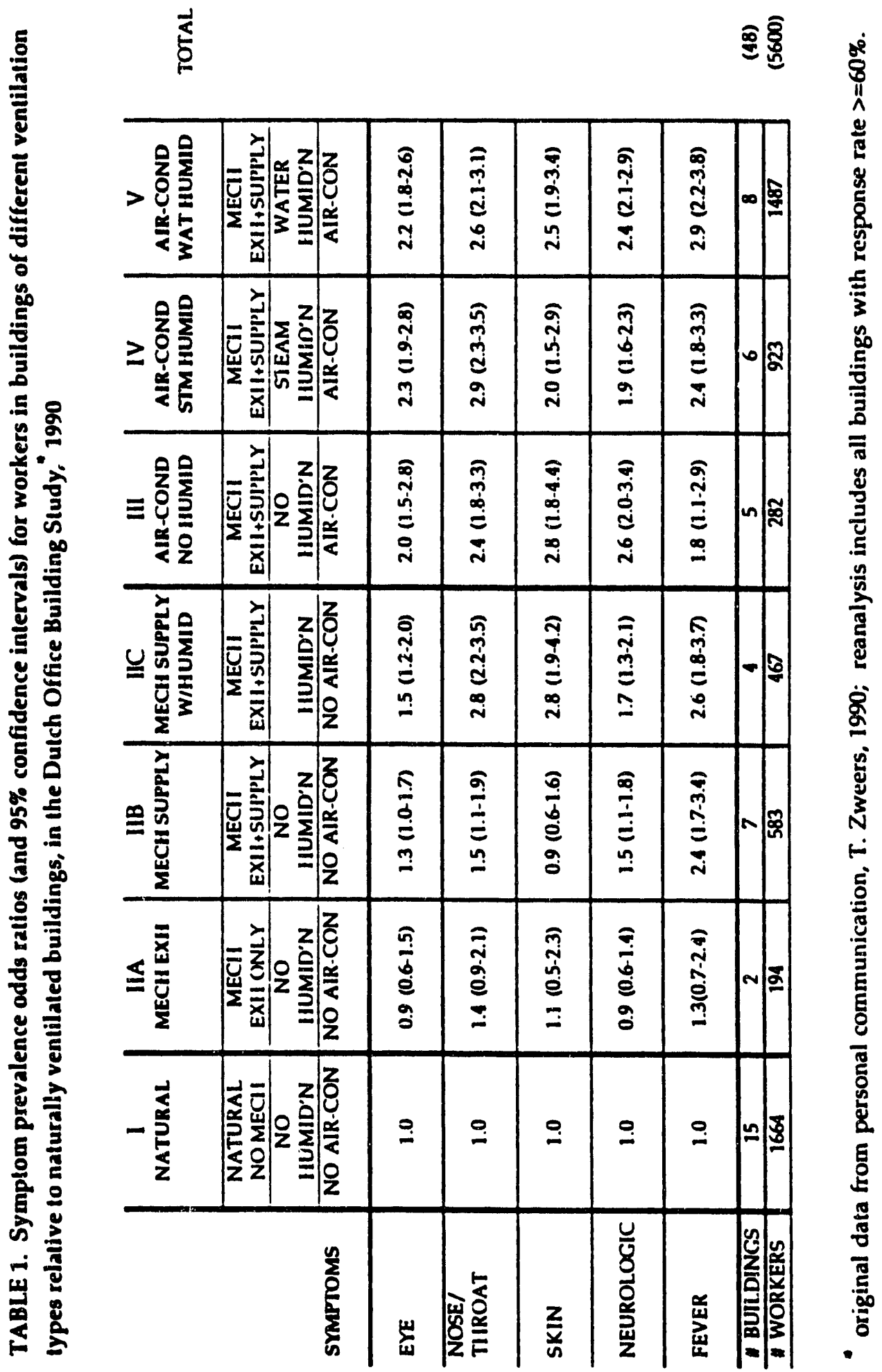


REFERENCES

1. Mage DT, Gammage RB: Evaluation of changes in indoor air quality occurring over the past several decades. In: Gammage RB, Kaye SV (eds): Indoor Air and Human Health: Lewis Publishers, Inc.,1985;5-36. Chelsea, Minn.

2. Tavris DR, Field L, Brumback CL: Outbreak of illness due to volatilized asphalt coming from a malfunctioning fluorescent lighting fixture. Am $J$ public Health $1984 ; 74: 614-615$.

3. Hodgson $M J$, Morey PE, Simon JH, Waters TD, Fink JH: An outbreak of recurrent acute and chronic hypersensitivity pneumonitis in office workers. Am J Epidemiol $1987 ; 125: 631-638$.

4. Anonymous: Indoor air quality investigations in office buildings. Ind Hyg News Rep 1986;29:1.

5. Boxer PB: Occupational mass psychogenic illness. J OcC Med $1985 ; 27: 867-872$.

6. Kreiss $K$, Hodgson $\mathrm{MJ}$ : Building-associated epidemics. In: Walsh PJ, Dudney CS, Copenhaven ED (eds): Indoor Air Quality: CRC Press, 1983;87-106.

7. White LE, Clarkson JR, Chang S: Health effects from indoor air pollution: case studies. J Comm Health $1987 ; 12: 147-155$.

8. Taylor PR, Dell'Acqua BJ, Baptiste MS, Hkang H, Sovik RA: Illness in an office building with limited fresh air access. J Environ Health 1984;47:24-27.

9. Chovil AC, Feigley CE, Crosscope E: An occupational illlness in a university setting. Am Ind Hyg Assoc J $1986 ; 47:$ A644-A646.

10. Whorton MD, Larson SR, Gordon NJ, Morgan RW: Investigation and work-up of tight building syndrome. $J$ Occ Med 1987;29:142-147.

11. Turiel I, Hollowell CD, Miksch RR, Rudy $J V$, Young RA: The effects of reduced ventilation on indoor air quality in an office building. Atmos Envir 1983;17:51-64.

12. Finnegan $M J$, Pickering CAC, Burge PS: The sick building syndrome: prevalence studies. Brit Med J 1984;289:15731575 .

13. Pickering AC, Finnegan $M J$, Robertson A, Burge S: Sick building syndrome. In: Berglund B, Lindvall $T$, sundell $J$ 
(eds): Indoor Air, Vol. 3: Sensory and hyperreactivity reactions to sick buildings. Proc of the International Conference on Indoor Air Quality and Climate, stockholm, 1984;321-325. Available from Swedish Council for Building Research.

14. Robertson AS, Burge PS, Hedge A, et al: Comparison of health problems related to work and environmental measurements in two office huildings with different ventilation systems. Brit Med J 1985;291:3733-3736.

15. Finnegan $M$, Pickering AC: Prevalence of symptoms of the sick building syndrome in buildings without expressed dissatisfaction. In: Seifert B. Esdorn H. Fischer $M$. Ruden H. Wegner $J$ (eds): Vol. 2, Indoor Air 187: Proc of the 4 th International Conference on Indoor Air Quality and Climate, Berlin, 1987;542-546. Available from Institute for Water, Soil and Air Hygiene, des Bundesgesundheitsamtes, Corrensplatz 1, D-1000 Berlin 33 .

16. Harrison $J$, Pickering AC, Finnegan $M J$, Austwick PKC: The sick building syndrome: further prevalence studies and investigation of possible causes. In: Vol. 2, Indoor Air 187: Proc of the 4th International Conference on Indoor Air Quality and Climate, Berlin, 1987;487-491.

17. Burge $S$, Hedge $A$, wilson $S$, Harris-Bass $J$, Robertson AS: Sick building syndrome: a study of 4373 office workers. Ann Occup Hyg 1987;31:193-504.

18. Hedge A, Wilson S, Burge PS, Robertson AS, harris-Bass $\mathrm{J}$ : Indoor climate and employee health in offices. In: vol. 2, Indoor Air 187: Proc of the 4th International Conference on Indoor Air Quality and Climate, Berlin, $1987 ; 492-496$.

19. Hedge A, Burge PS, Robertson AS, Wilson S, Harris-Bass $\mathrm{J}$ : Work-related illness in offices: a proposed model of the "sick building syndrome." Envir Intl 1989;15:143158.

20. Hedge A: Evidence of a relationship between office design and self-reports of ill health among office workers in the United Kingdom. J Arch Plan Res 1984;1:163-174.

21. Robertson AS: Building sickness -- are symptoms related to office lighting? Ann Occup Hyg 1989;33:47-59.

22. Skov $P$, Valbjorn O, Danish Indoor Climate Study Group: The "sick" building syndrome in the office environment: the Danish town hall study. Envir Intl 1987;13:339-349. 
23. Skov P, Valbjorn O, Pedersen BV, the Danish Indoor Climate study Group: Influence of personal characteristics, Job-related factors and psychosocial eactors on the sick building syndromw. Scand $J$ Work Environ Health $1989 ; 15: 286-295$.

24. Skov P, Valbjorn O, Danish Indoor Climate Study Group: The "sick" building syndrome in the office environment - the Danish town hall study. In: Vol. 2, Indoor Air 187: Proc of the 4th International Conference on Indoor Air Quality and Climate, Berlin, 1987;439-443.

25. Nielsen PA, Danish Indoor Climate study Group: Potential pollutants - their importance to the sick building syndrome and their release mechanism. In: Vol. 2, Indoor Air 187: Prnc of the 4th International Conference on Indoor Air Quality and Climate, Berlin, 1987;598-602.

26. Valbjorn O, Skov $P$, Danish Indoor Climate study Group: Influence of indoor climate on the sick building syndrome prevalence. In: Vol. 2, Indoor Air 187: Proc of the 4 th International Conference on Indoor Air quality and Climate, Berlin, 1987;593-597.

27. Finnegan $W$, Pickering CAC: Building rela ed illness. Clin Allergy $1986 ; 16: 389-405$.

28. Samet JM, Marbury MC, Spengler JD: Health effects and sources of indoor air pollution. part II. Am Rev Resp Dis $1988 ; 137: 221-242$.

29. Bardana EJ: Building-related illness -- a review of available scientific data. Clin R Allergy 1988;6:61-89.

30. Kreiss K: The epidemiology of building-related complaints and illness. Occup Med: State of the Art Rev $1989 ; 4: 1-18$.

31. Kleinbaum DG, Kupper IL, Morgenstern H: Epidemiologic Research: Principles and Quantitative Methods. Belmont, CA: Lifetime Learning Publications, 1986;301.

32. Checkoway H, Pearce NE, Crawford-Brown DJ: Research Methods in Occupational Epidemiology. New York: Oxford University Press, $1989 ; 216$.

33. Rothman KJ: Modern Epidemiology. Boston: Little, Brown and Company, 1986;67,70.

34. Newcombe RG: Towards a reduction in publication bias. Br Med J 1987;295:656-659. 
35. Begg CB, Berlin JA: Publication Bias and Dissemination of Clinical Research. J Natl Cancer Inst 1989; 81:107115 .

36. Sterling $E$, Sterling $T$ : The impact of different ventilation levels and fluorescent lighting types on . building illness: an experimental study. Can J Public Health $1983 ; 74: 385-392$.

37. Gravesen S, Larsen I, Gyntelberg F, Skov P: Demonstration of microorganisms and dust in schools and offices. Allergy $1986 ; 41: 520-525$.

38. Axelson 0: Aspects on confounding in occupational health epidemiology. Scand $J$ Work Environ Health 1984;10:325326.

39. Brundage JF, Scott RM, Lednar WM, Smith DW, Miller RN: Building-associated risk of febrile acute respiratory diseases in army trainees. JAMA 1988;259:2108-2112.

40. Arundel AV, sterling EM, Biggin JH, sterling TD: Indirect health effects of relative humidity in indoor environments. Environ Health Persp 1986; 65:351-361.

41. Ager BP, Tickner JA: The control of microbiological hazards associated with air-conditioning and ventilation systems. Ann Occup Hyg 1983; 27:341-358.

42. American Society of Heating, Refrigerating and AirConditioning Engineers: 1987 ASHRAE Handbook -- Heating, Ventilating, and Air-Conditioning systems and Applications. Atlanta: ASHRAE, 1987.

43. Hughes RT, O'Brien DM. Evaluation of building ventilation systems. Am Ind Hyg Assoc J 1986;47:207-213.

44. Mendell MJ, Smith AH. Consistent pattern of elevated symptoms in air-conditioned office buildings: a reanalysis of epidemiologic studies. Am $\mathrm{J}$ Public Health 1990; 80: 1193-1199.

45. Daisey JM, Fisk W', Hodgson AT, et al. The California Healthy Building Pilot study: I. Study design and protocol. Applied Science Division, Tawrence Berkeley Laboratory, Berkeley, CA, 1990, available from National Technical Information Service, LBI-29851 UC 350 . 
46. Cone JE, Hodigson MJ: Preface. Occup Med: State of the Art Rev 1989; 4:x-xii.

47. Indoor air quality and work environment study: Library of Congress Madison Building. National Institute for Occupational Safety and Health, U.S.E.P.A., John B. Pierce Laboratory, National Institute of standards and Technology. March, 1991

48. SAS Institute Inc., SAS/STAT User's Guide, Version 6, Fourth Ed., Cary, NC: SAS Institute Incl, 1989.

49. BMDP Statistical Software, Inc., BMDP Statistical Software Manual. Berkeley,CA: University of California Press : 1990.

50. Kroeling $P$. Health and well-being disorders in airconditioned buildings; comparative investigations of the "Building Ilness" syndrome. Energy and Buildings 1988; 11; 277-282.

51. Zweers T, Preller L, Brunekreef B, Boleij JSM. Relationships between health and indoor climate complaints and building, workplace, job and personal characteristics. Proc of the Fifth International Conference on Indoor Air Quality and Climate, Toronto, 1990. Volume 1, 495-500.

52. Skov P, Valbjorn O, Pedersen BV, the Danish Indoor Climate study Group. Influence of indoor climate on the sick building syndrome in an office environment. Scand $J$ Work Environ Health 1990; 16:1-9.

53. Harrison J, Pickering CAC, Faragher EB, Austwick PKC. An investigation of the relationship between microbial and particulate indoor air pollution and the sick building syndrome. Proc of the Fifth International Conference on Indoor Air Quality and Climate, Toronto, 1990. Volume 1, 149-154.

54. Burge PS, Jones, Robertson AS. Sick building syndrome. Proc of the Fifth International Conference on Indoor Air Quality and Climate, Toronto, 1990. Volume 1, 479-481.

55. Woods $J$ : Cost avoidance and productivity in owning and operating buildings. Occup Med: state of the Art Rev 1989; $4: 753-770$.

56. Norback D, Torgen M. A longitudinal study relating carpeting witb sick building syndrome. Environ Intl 1989; 15: 129-135.

57. Skov P, Valbjorn O, Danish Indoor Climate Study Group. The Danish Town Hall study -- a one year follow-up. Proc 
of the Fifth International conference on Indoor Air Quality and Climate, Toronto, 1990. Volume 1, 787-791.

58. Molhave $I$, Bach $R$, Pedersen OF. Human reactions to low concentrations of volatile organic compounds. Environ Int $1986 ; 12: 167-175$.

59. Otto D. Controlled exposure to low levels of volatile organic compounds. EPA Technical Report. Research Triangle Park, NC: Environmental Protection Agency; 1989.

60. Hodgson MJ, Frohliger J, Permar E, Tidwell C, et al. Symptoms and microenvironmental measures in nonproblem buildings. $J$ Occup Med 1991:33:527-533.

61. Gravesen S, Larsen I, Gyntelberg F. Skov P. Demonstration of microorganisms and dust in schools and offices: an observational study of non-industrial buildings. Allergy 1986;41:520-525.

62. Sundell $J$, Lindvall $T$, stenberg. Influence of type of ventilation and outdoor airflow rate on the prevalence of sbs symptoms. Proceedings of IAQ91:Healthy Buildings, meeting of Ameriucan Society of Heating, Refrigerating and Air-Conditioning Engineers, 1991.

63. Seppanen 0, Jaakkola JJK. Factors that may effect on the results of indoor air quality studies in large office buildirgs. Symposium on design and protocol for monitoring indoor air quality, NIOSH, Cincinnati, OH 1987

64. Jaakkola JJK, Heinonen OP, Seppanen O. Sick building syndrome, sensation of dryness and thermal comfort in relation to room temperature in an office building: need for individual control of temperature. Enviro Int $1989 ; 15: 163-168$.

65. Molhave L, Thorsen M. A model for investigations of ventilation systems as sources for volatile organic compounds in indoor climate. Atmos Environ 1991:25A:241-249.

66. Hedge A, Sterling TD, Sterling EM, Collett CW, et al. Indoor air quality and health in two office buildings with different ventilation systems. Environ Int $1989 ; 15: 115-128$.

67. Zweers $T$, Skov $P$, Valbjorn $D$, Molhave $I$, DISG. The effect of ventilation and air pollution on perceived indoor air quality in five town halls. Energy and Buildings 1990:14:175-181. 
68. Buring JE, Hennekens $C H$. Carbonless copy paper: a review of epidemiologic studies. J Occup Med 1991;33:486-495.

69. Hodgson M, Traven ND, Permar E, Karpf M, et al. Symptoms and the microenvironment in non-problem buildings. Proc of the Fifth International Conference on Indoor Air . Quality and Climate, Toronto, 1990. Volume 1, 549-554.

70. Norback D, Torgen M, Edling C. Volatile organic compounds, respirable dust, and personal factors related to prevalence and incidence of sick building syndrome in primary schools. Br J Med 1990; 47:733-741.

71. Harving $H$, Dahl $R$, Molhave. Lung function and bronchial reactivity in asthmatics during exposure to volatile organic compounds. Am Rev Respir Dis 1991; 143:751-754.

72. Marks JG, Trautlein JJ, Zwillich CW, Demers CW. Contact urticaria and airway obstruction from carbonless copy paper. JAMA 1984; 252:1038-1040.

73. Jaakkola JJK, Heinonen OP, Seppanen O. The occurrence of common cold and the number of persons in the office room. Proc of the Fifth International Conference on Indoor Air Quality and Climate, Toronto, 1990. Volume 1, 155-160.

74. Nexo E, Skov PG, Gravesen S. Extreme fatigue and malaise syndrome caused by badly cleaned wall-to-wall carpets? Ecol Dis 1983; 2:415-418.

75. Kreiss K, Gonzales MG, Conright KI, Scheere AR. Respiratory Irritation due to carpet shampoo: two outbreaks. Environ Int $1982 ; 8: 337-341$.

76. Leinster $P$, Raw $G$, Thomson $N$, Leaman $A$, Whitehead $C$. $A$ modular longitudinal aproach to the investigation of sick Building Syndrome. Proc of the Fifth International Conference on Indoor Air Quality and Climate, Toronto, 1990. Volume 1, 287-292.

77. Cochran WG. The effectiveness of adjustment by subclassification in removing bias in observational studies. Biometrics 1981;113:474-480.

78. Jantunen $M J$, Bunn E, Pasanen $P$, Pasanen A-I. Does moisture condensation in air ducts promote iungal growth? Proc of the Fifth International Conference on Indoor Air Quality and Climate, Toronto, 1990. Volume 2, 73-78.

79. Pasanen P, Tarhanen J, Kalliokoski P, Nevalainen A. Emissions of volatile organic compounds from air conditioning filters of office buildings. Proc of the 
Fifth International Conference on Indoor Air Quality and Climate, Toronto, 1990. Volume 3, 183-186.

80. Sverdrup CF, Nyman E. A study of microorganisms in the ventilation systems of 12 diferent buildings in Sweden. Proc of the Fifth International Conference on Indoor Air Quality and Climate, Toronto, 1990. Volume 4, 583-588.

81. Broder I, Pilger C, Corey P. Building related discomfort is associated with perception rather than measured levels of indoor environmental variables. Proc of the Fifth International Conference on Indoor Air Quality and Climate, Toronto, 1990. Volume 1, 221-226.

83. Samet JM, Utell $M$. The environment and the lung: changing perspectives. JAMA 1991;266:670-675.

100. Mendell $\%$. Health effects in office workers associated with ventilation systems: evidence from the first U.S. study. unpublished doctoral dissertation (Chapter 1), University of California at Berkeley, Program in Epidemiology, Berkeley, CA: October, 1991. 


\section{APPENDIX I}

Findings of the studies included in this reanalysis are summarized here; terms used to describe ventilation categories are from the studies themselves. The first study (12-15), involving eight buildings, found higher symptom prevalence associated with mechanical compared with natural ventilation, even higher symptom prevalence for buildings with air-conditioning, and the highest prevalence in buildings with air-conditioning and humidification. Whether air within air-conditioned buildings was recirculated did not markedly affect symptom prevalence.

The second study (16), involving 27 buildings, reported higher symptom prevalence in both buildings with mechanical ventilation and those with air-conditioning and humidification, compared to buildings with natural

ventilation. Increases in the two groups were similar. In this study, researchers included several buildings they suspected of having problems; they point out, though, that at that time the sick building syndrome was not known in the United Kingdom.*

The third and largest study (17-19), involving 47 buildings, found lower symptom prevalence in buildings with mechanical ventilation relative to those with natural ventilation, higher prevalence in buildings with airconditioning, and the highest prevalence in two subsets of

* Personal communication, J. Harrison. 
buildings with air-conditioning: those with evaporative humidification (18), and those with "water-based" airconditioning systems (this refers to method of cooling the building $(42,43)$ and is not related to type of humidification).

The fourth study (20), involving 5 buildings, found prevalence of all symptoms measured to be higher in airconditioned buildings relative to conventional (not defined in report), but prevalence of only one symptom higher in unconditioned buildings relative to conventional buildings. The fifth study (21), involving two buildings, found higher symptom prevalence in an air-conditioned, humidified building relative to a naturally ventilated one.

The sixth study $(22-26)$, involving 14 buildings (minimal data were reported on some additional buildings), found symptom prevalence in mechanically ventilated buildings higher, but not significantly so, than in naturally ventilated buildings. The oldest town halls had the lowest prevalence of symptoms.

The first two studies used physician-administered questionnaires, and defined work-related symptoms as those occurring more than twice in the previous year, and improving on days away from work $(12,16)$; symptoms were also required to have started or worsened since working in the current building, except for nose, throat, and eye symptoms in the second study. ${ }^{\star \star}$ All the other studies used ** Personal communication, A. Robertson. 
self-administered questionnaires. Studies 3 and 5 defined work-related symptoms as those occurring more than twice in the previous year and also improving on days away from work $(17,21)$. Study 4 defined work-related symptoms as those reported to occur frequently at work (20). Study 6 defined work-related symptoms as those occurring at least weekly and improving on days away from work (22). Although individual symptoms were assessed in this study, data were reported only on groups of symptoms.

All studies achieved high response rates among workers in buildings studied -- in study 1 from 75-97\% (12); in study 2 from $86 \%$ upward (16); in study 3 from 67-100\%, averaging $92 \%$ (17); in study 5 averaging $97 \%$ (21); and in study 6 from 61-93\%, averaging $80 \%$ (22).

No study reported outside air ventilation rates in buildings. In study 1, environmental measurements were taken in only two buildings, one with low and one with high symptom prevalence; no significant differences were found in the parameters measured -- dry bulb temperature, globe temperature, relative humidity, air moisture content, air velocity, positive and negative ions, carbon monoxide, ozone, and formaldehyde (14). In study 2 , levels of airborne particles, as well as viable fungal and bacterial microorganisms, were measured in all buildings studied; no associations were found with symptom prevalence (16). Study 6 reported that symptom prevalence was higher in buildings 
with greater amounts of high-surface-area materials and open shelving (24).

studies 1 through 5 assessed all buildings between.

November and March. ${ }^{\star *}$ Season of study was not reported for study 6 .

*** Personal communication, A. Hedge. 
Appendix 2 .

\section{THE HEALTHX BUTLDING STUDX CONSENT EORM \\ (Return this form to us with the questionnaire!)}

This study will tell your employer and building manager about worker experience in your office environment (though neither they nor anyone else at work will know your individual answers on the questionnaire).

All questionnaires will be kept locked up, and then destroyed after data analysis is complete. Results of the study will be provided in a report to you and other employees, to employee representatives, and to your employer; results will contain eroup date only without any personal identifiers.

\section{WOULD LIKE TO PABTICIPATE IN THE HEALTHY BUILDING STUDY:}

I have read the previous instructions for the "Healthy Building Study", and consent to participate.
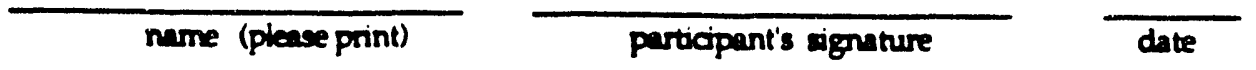

We will distribute to you a report of the study results when they are available.

NDT, PLEASE TURN TO THE BACK OF THIS PAGE.

LDONOT WANT TORARTOCTRATE RN THE HEALTHY BUILDNG STUDY:

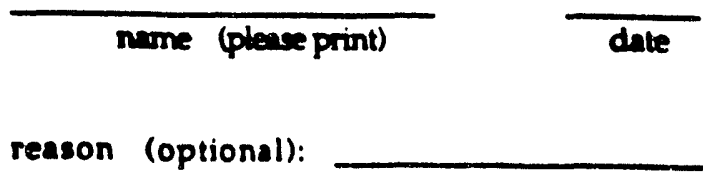

If you choose not to participate, please fold the blank questionnaire, eal it in the envelope provided, and retum it to the box marked Bullding Study", located near your mailbox. 


\section{PLEASE READ BEFORE COMPLETING OUESTIONNAIRE}

Many questions in this questionnaire mention either "LAST WEEK" or "LAST YEAR".

LAST YEAR refers to the 12-month period ending today. If you have worked in this building for less than one year, answer the "LAST YEAR" questions for that part of the year that you have worked in this building.

LAST WEEK refers to all days you worked from Monday through Friday of last week (not this week). Please report your ACTUAL EXPERIENCES LAST WEEK, even if last week was unusual for you. If you were not at work all of last week, answer for the most receni full week you were in the office.

Please fill out this questionnaire without discussing it or consulting about it with others: we want your own immediate opinions and responses.

We would like you to answer all the questions as completely as possible, but you do not have to answer any questions that you do not want to, and you may stop at any time. 


\section{PART I. DESCRIPTION OF YOUR WORKSTATION}

This section ank jou about jour workstation. Ds WORnstaTION we mean jour deak, oftce. cublcie, or plece thet 6 jour primers work area. If jou wort in mare then one becation, jour wortetation is the opectic bocation where you apend more the thin at ang other elingle beation.

1. There are many different types of workstations. Please check the categorles that best describe the space in which your current workstation is located.

a. Type of space (Check one)

1. Enclosed office with door

2. Not an enclosed ofnce, but with partitions or bookshelves giving you visual prtvacy on four sides

3. $\square$ Not an enclosed office, but with partitions or bookshelves giving you visual prtvacy on one. two. or three sides

4. $\square$ Open once area. with no visual privacy

5. $\square$ Other (specify)

b. Type of space sharing (Check one)

1. $\square$ One occupant only

2. $\square$ Shared with one other person

3. $\square$ Shared with two or more other persons

4. $\square$ Other (describe)
2. On what foor of the bullding do you work? (Enter the floor number, if the básement. write B.)

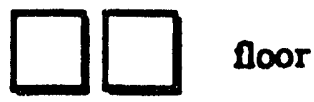

3. How long have you been workdng in the bullding? (If less than one year, enter number of months )

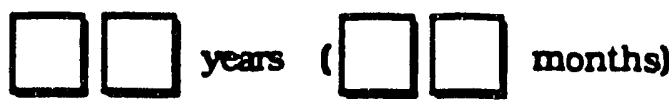

4. a. How long have you worked at your cument workstation? (If less than one year..enter number of months )

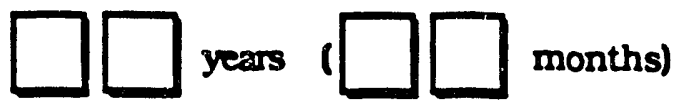

b. During an average workday, how many hours do you spend at vaur workstation?

$\square$ hours per day

5. a. During a typlcal week, how many hours do you work in the bullding?

$\square$ hours per WaAk

b. LAST WEEK, how many hours did you work in the bullding ?

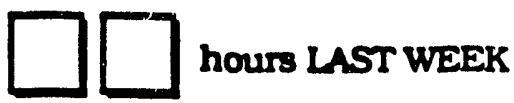


6. LAST WEER during a typical day . approdmately how much timc did you spend woriding with each of the following items? (If less than 1 hour per day. enter munutes.)

$$
\underset{\text { porday perday) }}{\text { hars }}
$$

a. Computer or word processor wth screen/keyboard

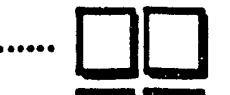

b. Photocopy machine .

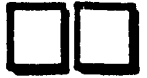

c. Carbonless coples (NCR papert)
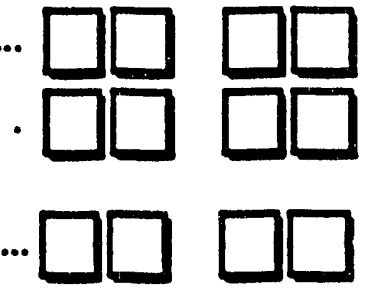

NOTE:

For the following questlons, think of the area withln a efrele of about 16 feet from your wortstation in all directlons.

7. Are any of the following items now located within 15 feet of your current workstation? (Check "no" or "yes" for each ttem)

$$
\text { No Yes }
$$$$
12
$$
a. Photocopy machine ....... $\square \square$
b. Laser printer................... $\square \square$
c. Plants ........................... $\square \square$
d. Window

(If No on "d" gete 0.9 )

8. Is there ever a window goen within 15 feet of your desk?
1. $\square$ No
2. $\square$ Yes

9. During the LAST YEAR (or ance you ve been at your current worketation. If that is less than a yearl have any of the following changes taken place within 15 feet of your current workstation? (Check "no" or "yes" for each ttem)

$$
\text { No Yes }
$$

a. New carpeting

b. New plants

c. Walls patnted

d Walls rearranged or moved 


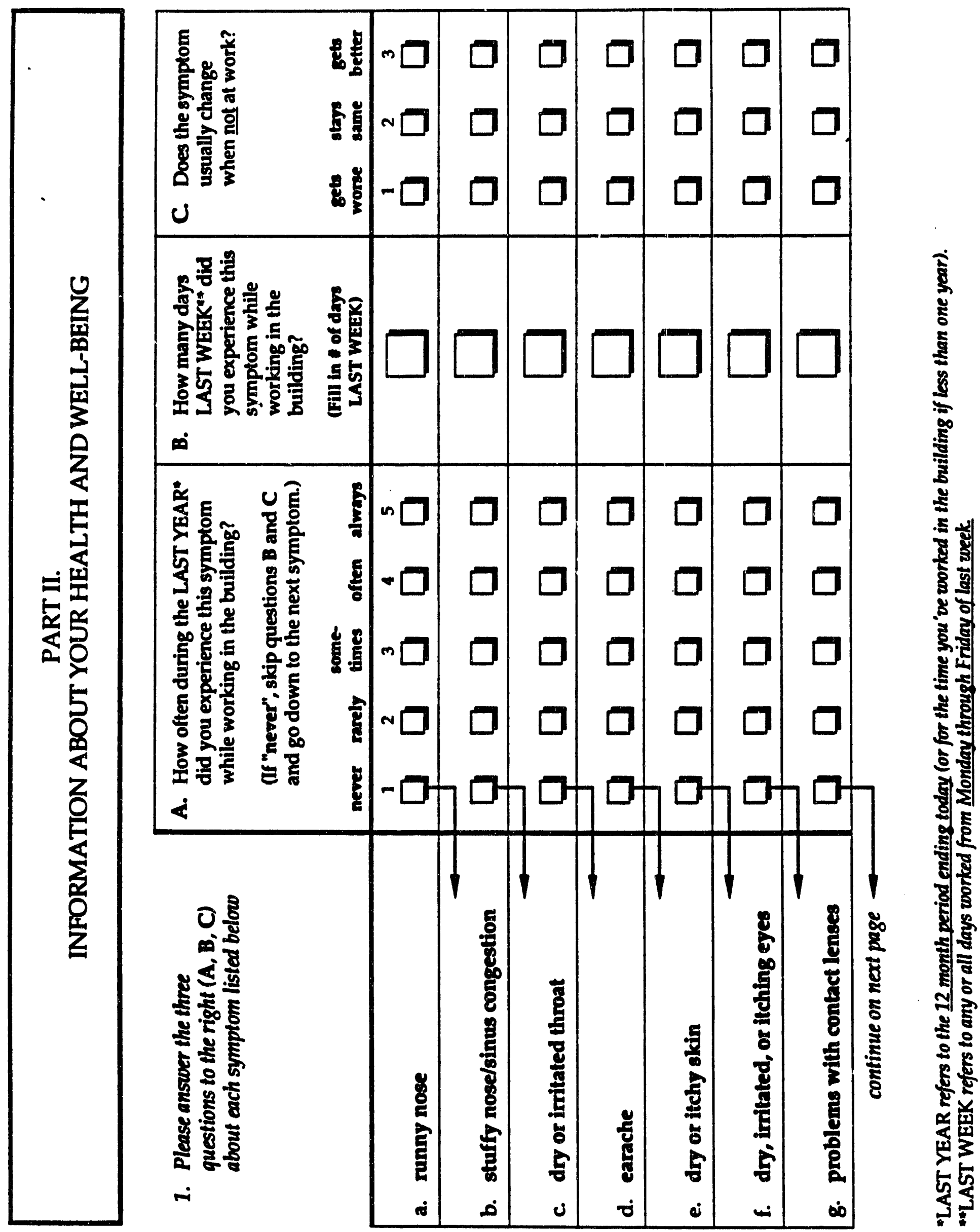




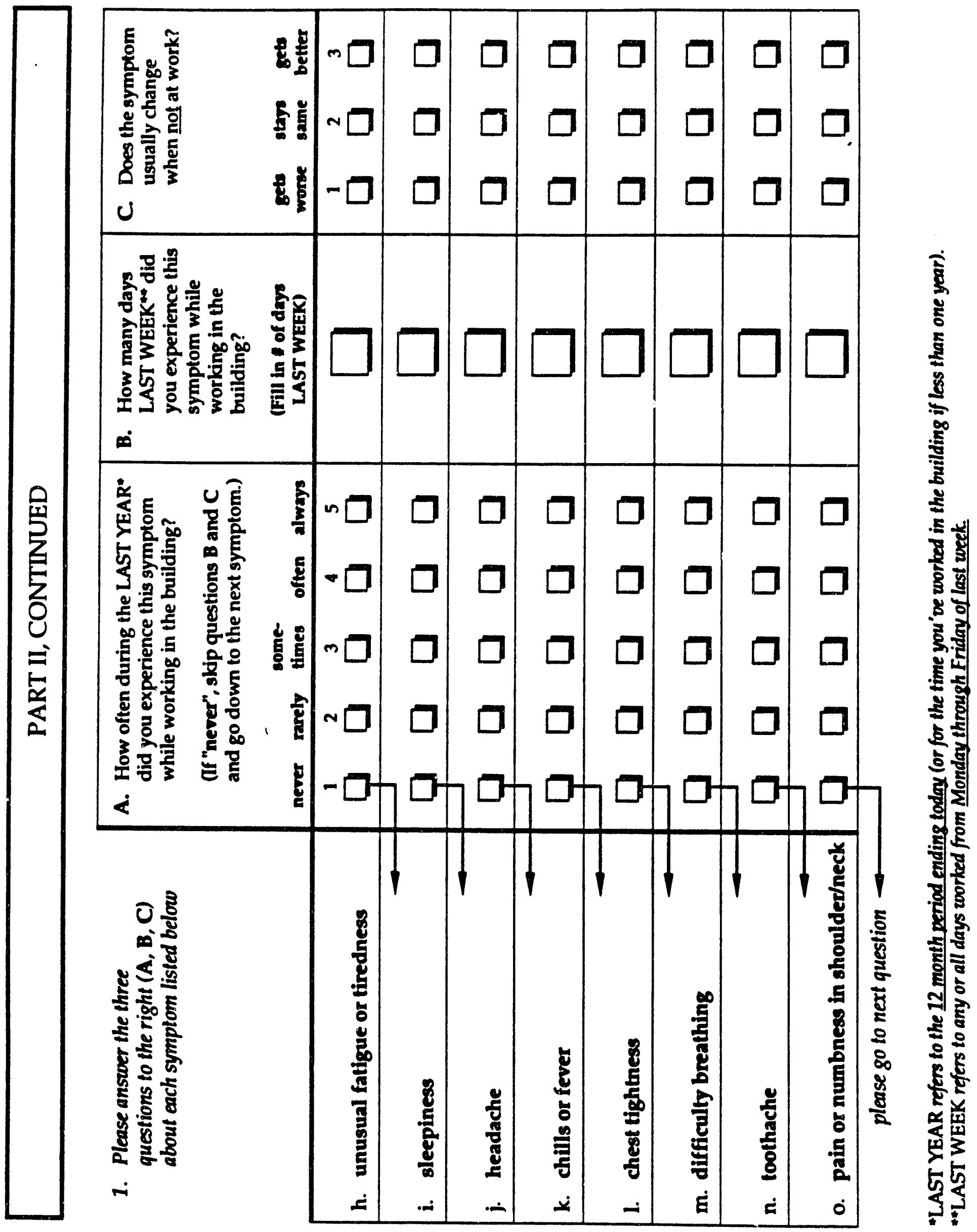


2. a. Today, do you have etther a cold, an tnfection tn your lungs or chest. or flu?
1. $\square$ No
2. $\square$ Yes

b. How many separate times in the LAST YEAR have you had elther a cold, an infection in your lungs or chest, or flu? (Write 0 y none.)

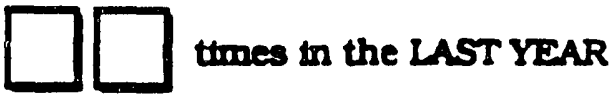

c How many times in the LAST YEAR have you seen a physictan because you had ether a cold, an infection in your lungs or chest, or Qu?

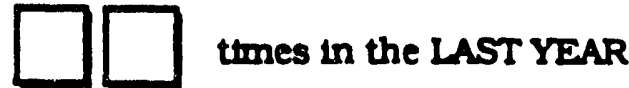

d. On how many days in the LAST YEAR has etther a cold, an inferstion in your hungs or chest. or Du caused you to stay home from work?<smiles>C1C2C3CC24C1C34</smiles>

days in the LAST YEAR

3. During the LAST YEAR, have you had an ilness in which you had repeated eptsodes of three or more of the following symptoms at the same time: wheeaing. cough, shortness of breath. fever, chills, aching Joints/muscles?
1. $\square$ No
2. $\square$ Yes

4. Durling the LAST YEAR, have you had any eplsodes of wheeaing (whistling in the chest) without fever or chills or sore throat?
1. $\square$ No
2. $\square$ Yes

5. a. Has a phyatctan ever told you that you have, or had. asthma?
1. $\square$ No $\longrightarrow$ (entongention 6$)$
2. $\square$ Yes

b. If yes, when was it first dlagnosed?

19<smiles>C1CC23CCC24CCC134</smiles>

c. Have you had an asthma attack during the LAST YEAR?
1. $\square$ No
2. $\square$ Yes

6. Do you belleve you are or may be allengle to any of the following? (Check "no" or "yes" for each Item.)

$$
\begin{array}{cc}
\text { No } & \text { Yes } \\
1 & 2
\end{array}
$$
a. pollen or plants
b. antroals
c. dust
d. malds
e. other (spectfy)

7. Do you wear contact lenses at work?

1. $\square$ Never

2. $\square$ Sometimes

3. $\square$ Often

4. $\square$ Always 


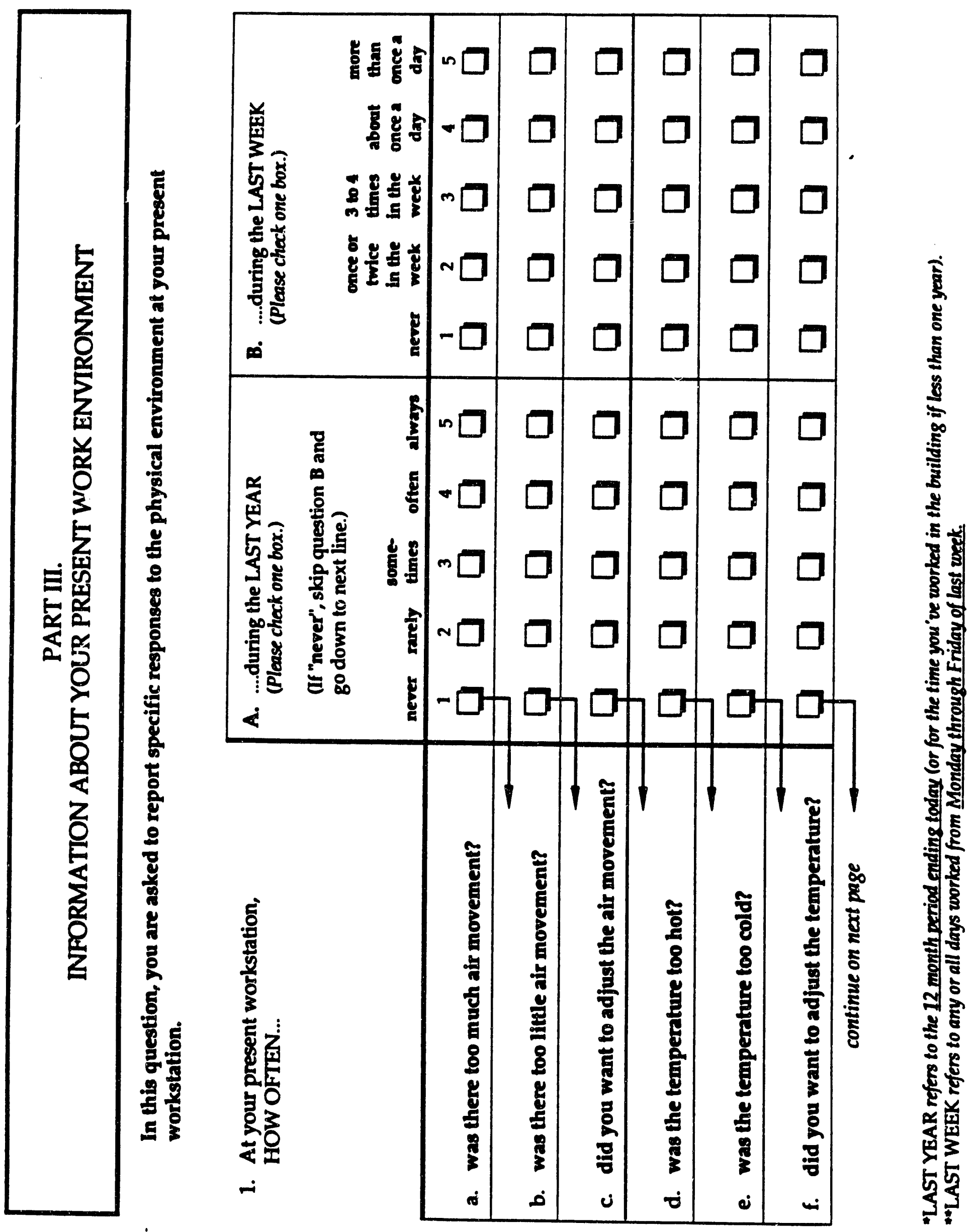



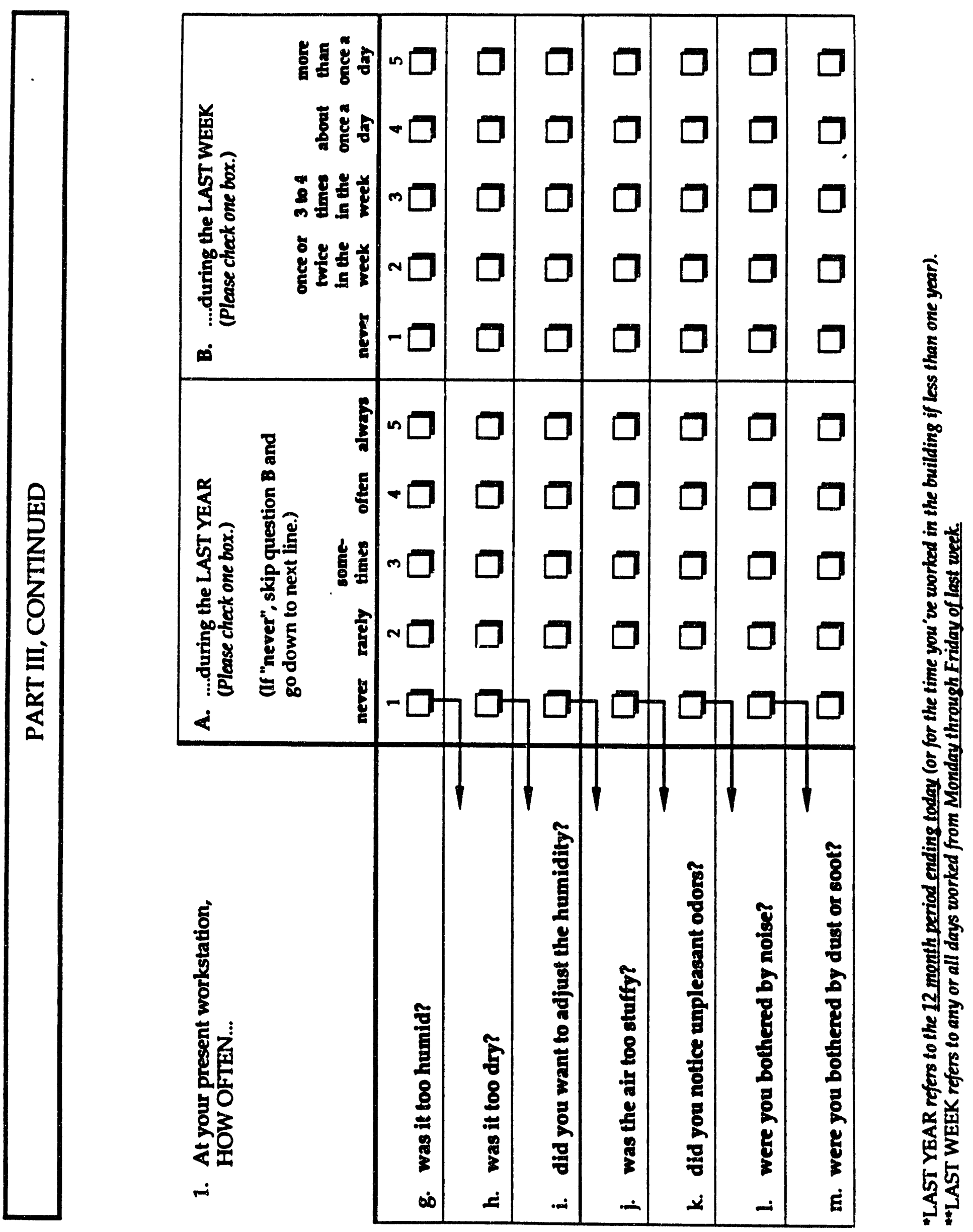
2. What kend of lighting do you generally use at your desk or workestation? (Check no or ves for each ttem.)
No Yes
12

a. Duorescent lights

b. ordinary light bulbs

c. natural light

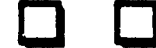

d. other (spectfy)

3. Please rate the lghting at your workstation.

1. $\square$ Much too dim

2. A little too dim

3. $\square$ Just right

4. $\square$ A little too bright

5. $\square$ Much too bright

4. Can you see out an outside window from your workstation?

1. $\square$ No

2. $\square$ Yes

5. How much matural daylight do you have at your usual desk or workstation? ( Check approprtate bax.)

1. $\square$ No natural daylight

2. $\square$ very little natural daylight

3. A moderate amount of natural daylight

4. $\square$ Much natural daylight
6. Are you promed or concerned about the tndoor atr where you work? (Check approprtate box.)

1. $\square$ not at all worried--> (ce teo Q.8)

2. $\square$ sightly wormed

3. $\square$ somewhat worried,

4. $\square$ very worried

7. If you are worried or concerned about the ventilation or indoor alr where you work. why is this? (Check no or ves for each item)

$$
\begin{array}{cc}
\text { No } & \text { Yes } \\
1 & 2
\end{array}
$$

a. because of some personal

comfort problems

b. because of some personal health problems ...............

c because of health problems of someone else in the bullding

d. because of things you have heard or read about certatn kands of bulldings

d. other (spectfy)

6. Compared to other office bulldings, how would you rate the indoor alr quality in your bullding? (Check appropriate box.)

1. $\square$ much better than others

2. $\square$ somewhat better than others

3. $\square$ about the same, or not sure

4. $\square$ somewhat worse than others

5. $\square$ much worse than others 
9. How antinfied are you with the following? (Check one box for each them, a through d.)

\begin{tabular}{|c|c|c|c|c|c|}
\hline & $\begin{array}{c}\text { Very } \\
\text { Eatinfed }\end{array}$ & $\begin{array}{l}\text { Montly } \\
\text { Eatisfied }\end{array}$ & Uncertaln & $\begin{array}{l}\text { Montly } \\
\text { Diesatisfed }\end{array}$ & $\begin{array}{c}\text { Very } \\
\text { Diseatiofied }\end{array}$ \\
\hline $\begin{array}{l}\text { a. control over the Honting } \\
\text { at jour worlostation }\end{array}$ & & & & & \\
\hline $\begin{array}{l}\text { b. control over the tempernture } \\
\text { at jour worlotintion }\end{array}$ & & & & & \\
\hline $\begin{array}{l}\text { c. control over the air movement } \\
\text { at jour wortsotation }\end{array}$ & & & & & \\
\hline 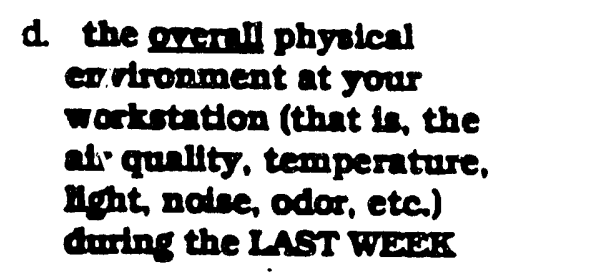 & & & & & \\
\hline 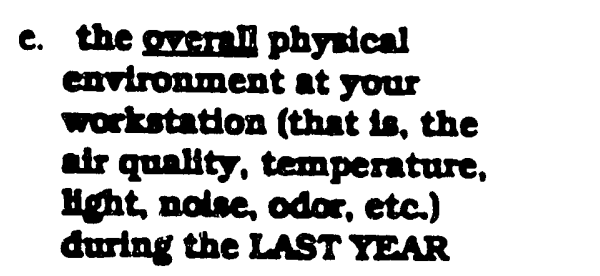 & & & & & \\
\hline
\end{tabular}




\section{PART IV. CHARACTERISTICS OF YOUR JOB}

1. Please say how much you agree or dlangree with each of the following statements about your job:

\begin{tabular}{|c|c|c|c|c|c|}
\hline & $\begin{array}{l}\text { 8trongly } \\
\text { Apree }\end{array}$ & $\begin{array}{l}\text { Mostly } \\
\text { Agree }\end{array}$ & Uncertaln & $\begin{array}{l}\text { Mostly } \\
\text { Dieagree }\end{array}$ & $\begin{array}{l}\text { Btrongly } \\
\text { Dlangree }\end{array}$ \\
\hline a. Yy job is wowity interesting & & & & & \\
\hline b. Im hypps to mo jab & & & & & \\
\hline c. I chatre my job & & & & & \\
\hline d. I am anthed with my Job & & & & & \\
\hline e. Tm enthwerastic about my job & & & & & \\
\hline f. My job ts ruther monotonous & & & & & \\
\hline g. My job bo not very otreaceful & & & & & \\
\hline h. I wounly hrve to work fint & & & & & \\
\hline 1. I caen feel stresced at work & & & & & \\
\hline J. Yo job demindis a lot of & & & & & \\
\hline k. I ctien feel overwotited & & & & & \\
\hline $\begin{array}{l}\text { 1. I hive a lot of control over how my } \\
\text { worts is done }\end{array}$ & & & & & \\
\hline $\begin{array}{l}\text { In. I hive enowis wpace in my wort } \\
\text { erea to do my work }\end{array}$ & & & & & \\
\hline $\begin{array}{l}\text { n. At qunlty in the ofice has cavied } \\
\text { beakth problems for me }\end{array}$ & & & & & \\
\hline $\begin{array}{l}\text { o. My wodopace gives me } \\
\text { adequnte firual patracy }\end{array}$ & & & & & \\
\hline
\end{tabular}




\section{PART V. CONCLUDING QUESTIONS}

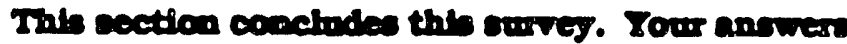
to these questlona, Mre your axwers to the prevlows quections, will be kept conodentinl. This informition beeded for otatiotical purposea.

1. Are you :
1. $\square$ Male
2. $\square$ Female

2. What was your age on your last blrthday? (Check appropriate box.)

1. $\square$ less than 20

2. 20.29

3. $\square 30.39$

4. $\square 40.49$

5. $\square 50.59$

6. $\square 60$ or over

3. a. What is your race/ethnic group? (Check the appropriate box.)
1. $\square$ White
2. $\square$ Black
3. $\square$ Astan/Pactfic Islander
4. $\square$ Other (spectfy)
5. $\square$ Decline to state

b. Are you of Spanish/Hispanic origin?
1. $\square$ No
2. $\square$ Yes
3. $\square$ Decitne to state

4. Which of the following best describes your Job duties and responalbilties? (II more than one applies, check the ONE box for the job duties on which you spend the most time.)

\section{1. $\square$ Managertal (such as administrator, manager, etc.)} 2. $\square$ Professional (such as engineer,
scientist. lawyer, etc.)

3. $\square$ Technical (such as techniclan. programmer. etc.)

4. $\square$ Administrattve Support (such as clerical, secretartal, word processing. key entry, etc.)

5. $\square$ Other (spectry)

5. What is the highest grade you completed in school?

1. 11 th grade or less

2. $\square$ High school graduate

3. 2 years of college or Assoctate Degree

4. Bachelor's or technical degree

5. $\square$ Some graduate work

6. Graduate or professional degree 
6. a. Which of the following best describes your history of smokdng tobacco products such as cigarettes, clgars, or plpes?

1. $\square$ Never moked- $>$ ( sato 0,0

2. $\square$ Former smoker

3. $\square$ Current smoker

b. In a typical 24 hour day, how many CIGARETTES do you usually smoke?
1. $\square$ None
2. 1 to 5
3. $\square 6$ to 10
4. $\square 10$ to 20
5. 21 or more

7. Gtve the date when you finished this questionnaire:

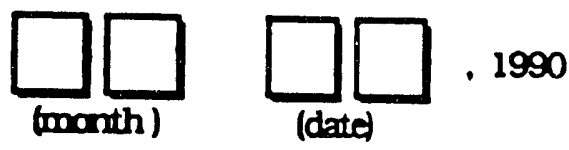


10. Is there anything else you would like to tell us about environmental or health matters in your bullding? If 80 . please use this space provided for that purpose:

When you are finithed, please:

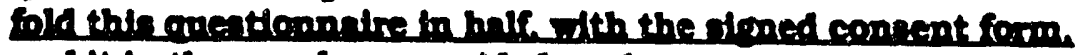

cellit in the envelope prodded end

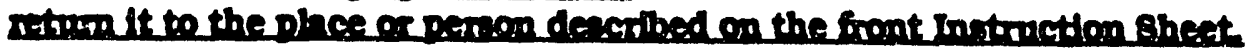

THANE YOU VERT MUCE FOR YOUR TWEE AND PATIENCE IN EUIING OUT TEIS gUESTIONRALRE. 

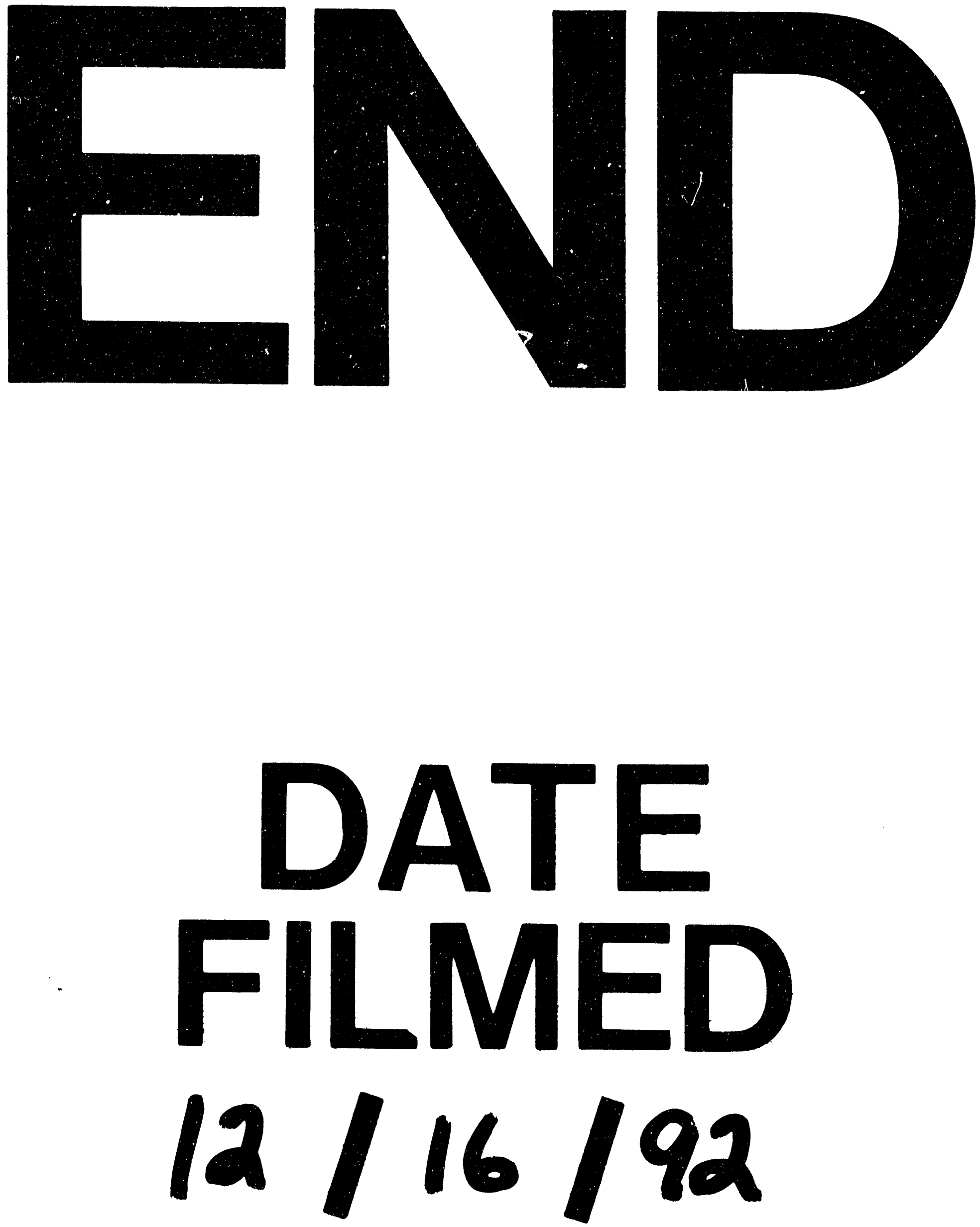